\title{
Hydrodynamics of gas-solids flow in a bubbling fluidized bed with immersed vertical U-tube banks
}

\author{
Vikrant Verma ${ }^{a^{*}}$, Tingwen Li $^{\text {a,b }}$, Jean-François Dietiker ${ }^{a, c}$, William A. Rogers ${ }^{a}$ \\ ${ }^{a}$ National Energy Technology Laboratory, Morgantown, WV 26505, USA \\ ${ }^{\mathrm{b}}$ AECOM, Morgantown, WV 26505, USA \\ ${ }^{\mathrm{c}}$ West Virginia University Research Corporation, Morgantown, WV 26506, USA \\ *Email addresses: dr.v.vikrant@gmail.com, Fnu.Vikrant@contr.netl.doe.gov
}

\begin{abstract}
\end{abstract}
We apply a two-fluid model (TFM) from the open-source code Multiphase Flow with Interphase eXchanges (MFIX) to investigate hydrodynamics in a gas-solids fluidized bed with immersed vertical tubes. The cut-cell method implemented in MFIX is used to fully resolve the flow around vertical U-tube banks. Simulations are performed in a bed diameter of $0.145 \mathrm{~m}$ with square and triangular tube arrangements, for inlet gas velocities of $\mathrm{U}_{0} / \mathrm{U}_{\mathrm{mf}}=2.3,4.5$ and 6.8. Simulation results are compared with experimental results from the literature and show very good agreement for the bubble size. The efficiency of vertical tubes in reducing bubble size depends upon inlet gas velocity and tube arrangement. Reduction in bubble size is due to the vertical tubes preventing bubble coalescence and promoting bubble splitting. In-bed vertical tubes result in uniform distribution of bubbles within the bed with increase in bubble frequency. The bubble frequency is higher within the bed for square tube arrangements. For a bed with vertical tubes, the bubble shape is generally elongated, which results in high bubble rise velocity. Axial solid velocity and solids circulation patterns are significantly affected by the vertical tubes, where triangular tube arrangements rarely show any solids circulating zone.

Keywords: fluidized beds, vertical tubes, two-fluid model, hydrodynamics, bubble. 


\section{Introduction}

7 Gas-Solids fluidized beds are widely used in industrial operation due to their large contacting area

8 between gas and solids, which enhances chemical reactions, heat and mass transfer. The performance of a

9 fluidized bed is primarily governed by the formation of gas bubbles and their distribution, facilitating

10 rapid solids mixing and high heat transfer rates to immersed surfaces. Formation and propagations of

11 these gas bubbles in a fluidized bed is a fairly complicated process influenced by many factors such as

12 properties of gas and particulate phase, bed operating conditions, reactor geometry and presence of

13 internal objects. Many experimental and numerical studies [1-6] are available in the literature to

14 understand complex hydrodynamics in fluidized beds. However these studies are mainly for 2D or 3D bed

15 without taking into account the presence of in-bed tubes. Presence of in-bed tubes has several advantages.

16 Initially those tubes were introduced to prevent slugging in the bed, where bubble size can reach the bed

17 diameter. Almstedt and Jin et al. [7, 8] suggested that in-bed tube geometries offer a fairly well-defined

18 bubble path up through the bed, as the bubbles grow to a limited size in free passage between the tubes. If

19 there are many such free bubble paths in a wide bed, the bed as a whole will not show a slugging

20 behavior. In many industrial fluidized beds, submerged tubes (i.e heating or cooling tubes) are used to

21 enhance heat and mass transfer. In addition to acting as a heat exchanger these submerged tubes also alter

22 the hydrodynamics significantly. It is well known that presence of these tubes affects the bubble growth

23 significantly, such as preventing them from coalescence and forcing large bubbles to split [8, 9]. The

24 splitting of bubbles results in redistribution into emulsion phase and a homogenous distribution of

25 bubbles across the reactors $[10,11]$. Thus fundamental understanding of bubble behavior in fluidized beds

26 containing in-bed tubes has significant practical importance for the design and scale-up of these reactors 
$[12,13]$. However, complex hydrodynamics due to continuous interactions of the dense tubes with rising

2 bubbles are not yet fully understood and therefore require detailed investigation.

3 Hydrodynamics studies on the effects of design configurations, such as the orientation and arrangement of

4 tubes, tube diameter, tube spacing and the distance between the tube bank and gas distributor have been

5 reviewed $[8,14]$ Many experimental studies are available to study the effect of submerged tubes on

6 hydrodynamics, and heat transfer characteristics. Majorities of the studies [15-19] are for in-bed arrays of

7 horizontal tubes only. Horizontal tubes are found to be effective for splitting bubbles into daughter

8 bubbles, but show relatively poor heat transfer coefficient at the bottom and top of the horizontal tubes

9 due to formation of stagnant zones [8]. Under some circumstances, horizontal tubes cause daughter

10 bubbles to recombine, thus nullifying the beneficial effect of splitting [20]. Formation of dead zone at the

11 top and bottom of horizontally aligned tubes is a major industrial problem in operating fluidized beds. To

12 overcome such a problem vertical tubes alignment are preferred over horizontal tubes. Vertical alignment

13 of tubes provides high heat transfer rate and low erosion. Moreover vertical tubes divide the bed into

14 number of parallel longitudinal compartments standing side by side, simplifying the scale-up [8, 9]. A

15 significant drawback of vertical tubes compared to freely bubbling fluidized beds is their reduction of

16 axial and lateral solids mixing, such that particle segregation is promoted and proper fluidization becomes

17 difficult due to channeling $[10,21,22]$. However these can be prevented by choosing proper tube

18 diameter and spacing, where spacing between adjacent tubes of at least 30 particle diameters is effective

$19[8,9]$.

20 There has been limited work published in the literature for in-bed vertical tubes, and this has limited

21 applications to design and scale-up purposes. Detailed investigation on bubble characteristics and solids

22 motion in fluidized beds with vertical tube are not reported yet. This may be due to limitations of

23 experimental measurement techniques, which becomes difficult to perform with vertical tubes inside the

24 beds. Rudisuli et al. [11, 23] studied small scale fluidized beds with vertical tubes, using pressure

25 fluctuation measurements and optical probe measurements to extract bubble characteristics. They [11, 23] 
1 studied different vertical tube configurations at different inlet gas velocities. They found significant

2 reduction in bubble size at higher gas velocities, and for narrow tube spacing, when compared to bed

3 without tubes. For the same flow condition, they also observed different bubble sizes, when different

4 measurement techniques (pressure fluctuation measurements and optical probe) were used. They have

5 shown encouraging results on bubble size and frequency. To a certain extent they succeeded to investigate

6 bubble rise velocity using optical probe measurement. Unfortunately, the measurement techniques they

7 applied have some limitations, and are unable to capture the bubble shape factor and solid flow patterns.

8 Almost all studies available in the literature regarding the effect of horizontal/vertical tubes focus on 9 experimental measurements. Only few numerical studies [24-27] report the effect of tubes inside fluidized

10 beds. Even these studies are mainly limited to 2D system with horizontal tubes, and mainly deal with

11 microscopic tube-bed heat transfer coefficients. To our knowledge no numerical study is available to

12 show the effect of vertical tubes on bubble characteristics and solids motion inside fluidized beds. This is

13 possibly due to the high computational cost and difficulty to represent banks of tubes using structured

14 grids. Although it is fairly reasonable to study a two-dimensional cross section of the bed when horizontal

15 tubes are present, numerical simulations with vertical tubes must be performed with three-dimensional

16 geometries. Fortunately, with increasing computational power and recent development in computational

17 algorithm to resolve internal objects, it has become possible to conduct three-dimensional simulations of

18 complex geometry systems. Therefore in this work we take the advantage of cut-cell method [28, 29] in

19 MFIX, to investigate hydrodynamics of 3D fluidized beds containing vertical U-tubes banks. The

20 motivation of this study arises from carbon capture units, which has been principally designed to contain

21 number of vertical U-tube banks. This study will provide proper understanding on the hydrodynamics in

22 such units. On the other hand comparison with experimental results and finding in the literature will show

23 the reliability of CFD models to study such complex geometries.

24 Discrete element modeling (DEM) and two-fluid modeling (TFM) are two common modeling approaches 25 to study fluidized beds. In DEM, the gas phase is considered as the continuous phase whereas the particle 
1 trajectories are obtained by integrating Newton's equation of motion. Such model quickly becomes

2 computationally too expensive because of large number of particle interactions. Therefore TFM is

3 preferred over DEM, treating gas and solids phases as fully interpenetrating continua, and particle-particle

4 interaction is taken into account using kinetic theory of granular flow. Many studies available in the

5 literature have used TFM continuum approach to predict hydrodynamics successfully. In this work we

6 used TFM from open-source code MFIX, incorporating state of art cut-cell method to resolve internal

7 vertical U-tubes.

8 This paper is organized as follows. First, a general description of TFM is given in section 2 and the cut-

9 cell method used to accommodate vertical U-tube bundles is then introduced in section 3. Details on bed

10 geometry and simulation setting are given in section 4. Details on post-processing of simulation data to

11 obtain bubble characteristics and solids motion are given in section 5. Subsequently, section 6 comprises

12 the results and discussions including experimental comparison from Rudisuli et al. 2012a and finally the

13 conclusions are drawn.

\section{Two-Fluid Model}

15 The two-fluid continuum model describes both the gas phase and the solids phase as fully interpenetrating continua using a generalized form of the Navier-Stokes equations. The gas and solid phases are coupled

17 through the interphase momentum transfer coefficient in the momentum equations. The Gidaspow drag

18 force model [30] is used in this work. A summary of conservation equations are given in Table 1. Kinetic

19 theory of granular flow [30,31] has been used to take into account the particle-particle interaction

20 explicitly using granular temperature. Instead of the more detailed partial differential equation

21 formulation, a simple algebraic approximation of the granular energy equation is used (Table 1 eq. T1-3),

22 simplified by neglecting the convection and diffusion components of granular energy equation. This is a

23 necessary choice to allow using the Cartesian grid cut-cell method of MFIX [29] to model vertical tubes

24 inside fluidized beds and the cylindrical domain itself on Cartesian staggered grids. Bakshi et. al. [32]

25 used an algebraic approximation for granular energy to perform simulations for bubbling beds and found

26 good agreement with experimental results. Furthermore references [27, 33] have used the cut-cell feature 
implemented in MFIX with an algebraic approximation for granular energy to model a horizontal tube bundle in a bubbling bed. Their simulation results show reasonably good agreement with experimental measurements of bubble frequency and bubble phase fraction, suggesting that the algebraic approximation is an acceptable simplification. Further details of governing equations solved in MFIX are summarized in reference [34]. Details on theory and numerical techniques can be found at https://mfix.netl.doe.gov [35,36].

\section{Cartesian Cut-Cell method}

In the cut-cell method, a Cartesian grid is used to discretize the computational domain while the boundary cells are truncated so that they conform to the boundary surface. This method retains the advantages of a Cartesian grid formulation in the standard, non-boundary cells and additional treatment is required only for the boundary cells. Hence, it is very suitable for adoption in legacy Cartesian grid CFD solvers to represent complex geometries. Details about the Cartesian grid cut-cell method can be found in Kirkpatrick [37] and the MFIX implementation is described in references [28, 29].

To provide an overview, the following three steps are involved in the implementation and utilization of the cut-cell technique. First, as a pre-processing step, the geometry is defined as a collection of quadric surfaces which are intersected with the background Cartesian grid. Computational cells are truncated to conform to the shape of the boundaries and newly formed cut-cell volumes and face areas are updated. Velocity nodes are moved to the center of cut-cell faces. During computation of the flow field, fluxes are evaluated based on the new geometry and the location of velocity nodes. An additional term, arising from the contribution of the cut face shear stress, is included in the computation. Non-orthogonality correction terms are included in the computation of velocity gradients. Finally, post-processing tools have been modified to visualize the shape of cut-cells. Fig.1 (a) and (b) illustrate a typical computational grid near a curved boundary, along with velocity nodes. The thick solid line represents the wall boundary and three types of cells are shown: (1) standard (uncut) cells; (2) cut-cells that require special treatment to incorporate the presence of the solid wall; and (3) blocked cells that are excluded from computations since they are located outside the active computational domain. A no-slip or free-slip velocity boundary condition can be applied for each phase at the wall. For more details on implementation and incorporation of U-tube shapes readers are referred to Dietiker [28]. 


\section{Simulation Settings}

2 An experimental set-up described by Rudisuli et al. [23] is considered in this work. They performed 3 experiments on a $0.145 \mathrm{~m}$ diameter fluidized beds using aluminum oxide particles, for inlet gas velocities 4 of $\mathrm{U}_{0} / \mathrm{U}_{\mathrm{mf}}=2.3,4.5$ and 6.8 , and a variety of vertical U-tubes configurations inside the bed. They 5 measured pressure fluctuation time series at several heights within the bubbling bed using a piezoelectric 6 pressure transducer. They obtained bubble size by means of the spectral data decomposition of pressure 7 fluctuation measurements. Corresponding details for our simulation settings are given in Tables 2 and 3.

8 The $\mathrm{U}_{\mathrm{mf}}$ calculated from drag force model is found to be $0.042 \mathrm{~m} / \mathrm{s}$, which is close to the measured value 9 of $0.041 \mathrm{~m} / \mathrm{s}$ from Rudisuli et al. [23]. Therefore in this work we took $U_{\mathrm{mf}}$ value of $0.041 \mathrm{~m} / \mathrm{s}$ as mentioned in Table 3. We performed simulations for two different tube configurations, i.e. square and

11 triangular arrangements with the tubes $15 \mathrm{~mm}$ in diameter. We made this choice because these configurations have the same tube diameter and tube spacing but different tube arrangements.

13 Experimental results show that these two arrangements are efficient in reducing bubble size. As their 14 names suggest, the square tube arrangement illustrates an in-line tube position forming squares, whereas 15 the triangular tube arrangement forms equilateral triangle with the tubes. The square tube arrangement results in large empty space near the column wall, which is filled by vertical auxiliary tubes in the experiments, and we followed the same arrangements for this work. For details on tube arrangements, the reader is referred to [23]. Fig. 2 (a) and (b) shows the geometry created for simulations with square and triangular tube arrangements respectively. Details about the geometry and computational grids are presented in Table 3. Details of TFM simulation settings can be found in Table 2. A non-slip boundary condition was applied for both gas and solid phases on the tube surface and the side walls. A uniform gas inflow from the bottom and a pressure outflow at the top exit were specified. The second order discretization Superbee scheme was used for solving the governing equations. MFIX uses a variable time

24 step which is automatically adjusted to maintain stability and reduce run time. Typically, the maximum time step achieved in our simulations was in the order of $10^{-4} \mathrm{~s}$. Three operating conditions corresponding to $\mathrm{U}_{0} / \mathrm{U}_{\mathrm{mf}}=2.3,4.5$ and 6.8 were simulated. Here the superficial gas velocity was determined based on the cross-sectional area at the inlet. Please note that we did not take into account the effect of reduced area due to immersed tubes on the superficial gas velocity. The reduced area is nearly the same for both square and triangular tube arrangements. We performed simulations for isothermal and non-reactive flow for a 
1 total time of $20.0 \mathrm{~s}$. Time-averaging was performed after neglecting the first second of simulation time to

2 avoid inclusion of start-up effects. The data sampling frequency is 125 frames per second.

\section{Post-processing}

4 Post-processing of 3D simulation data is crucial to calculate bubble properties such as bubble size and

5 bubble rise velocity. It becomes further challenging when bubbles continuously interact with vertical

6 tubes because the bubble definition may not be straight forward. From 3D simulation animations, we have

7 seen that for a given tube configuration bubbles can rise along the vertical tube. To perform actual

8 calculation on bubble properties and solids motion, we choose a measurement plane inside the fluid bed,

9 where no or few number of tubes intersects that plane. Typically this plane is located in the center of the

10 bed, between and parallel to the vertical tubes. We feel this the best possible measurement plane to

11 illustrate the effect of vertical tubes on the bed hydrodynamics. To calculate the bubble characteristics,

12 the gas volume fraction (voidage) is used. Voidage data is available in every computational cell within

13 the measurement plane. A threshold voidage value of 0.80 is used to define the bubble boundary, as

14 suggested by many authors [38]. Verma et al. [39] have reported bubble behavior using three different

15 approaches to define the bubble in a 3D domain as follows: the bubble defined by the 2D bubble area in a

16 plane inclined vertically to the bubble; a plane oriented horizontally to the bubble; and using the

17 equivalent bubble size from the full 3D bubble volume. They compared results from these three bubble

18 definitions in beds of different diameters. They found that both the 2D and 3D bubble definition are in

19 good agreement with literature correlations for bed diameters less than $0.30 \mathrm{~m}$. However for bed

20 diameters greater than $0.30 \mathrm{~m}$, bubble definition from 2D planes should be used with caution. Since in our

21 simulations the bed diameter is $0.15 \mathrm{~m}$, bubble properties are extracted from a $2 \mathrm{D}$ vertical measurement

22 plane as given by equation (1) where $\mathrm{N}_{\mathrm{b}}$ represents the number of predicted bubbles and $\mathrm{A}_{\mathrm{b}, \mathrm{i}}$ is the area of

23 an individual bubble. The number of predicted bubbles $\mathrm{N}_{\mathrm{b}}$ is used to obtain the average equivalent bubble

24 diameter.

25 Equivalent bubble diameter $=\frac{1}{N_{b}} \sum_{i=1}^{N_{b}} \sqrt{\frac{4 A_{b, i}}{\pi}}$ 
1 In the work of Rudisuli et al. [23] bubble size is evaluated from PFM by means of spectral data

2 decomposition, which provides a characteristic length scale proportional to the bubble size. The

3 proportionality constant to obtain equivalent bubble size from PFM have been discussed in Rudisuli et al.

$4 \quad$ [40]. In this work we compare actual bubble properties as given in Rudisuli et al. [23].

5 The bubble shape is characterized by the bubble aspect ratio given by ratio of maximum vertical length to

6 the horizontal length of the bubble. The bubble distribution is the number of bubbles detected in each

7 frame i.e. number of bubbles per frame.

8 The bubble rise velocity is calculated using a bubble tracking method [39] that considers individual

9 bubble motion. In this approach, the displacement of the centroid of each bubble is traced at a given time

10 frequency $(125 \mathrm{fps})$. The net movement of the bubble centroid with time provides the bubble rise

11 velocity. The averaged bubble rise velocity is obtained from an arithmetic average of individual bubble

12 velocities.

13 Solids flow characteristics are compared for solids circulation patterns and solids axial velocity in the

14 measurement plane. Equation 2 shows the expression for time-averaged axial solids velocity.

$15 \quad u_{a x i a l, s}^{a v g}=\frac{\sum \phi_{s} u_{a x i a l, s}}{\sum \phi_{s}}$

16 Where $\phi_{s}$ is the solids concentration and $u_{\text {axial }, s}$ is the axial solids velocity.

\section{Results and Discussion}

In this section we investigate the effect of vertical tubes on bubble characteristics and solids motion. The

19 bubble characteristics are based on the equivalent bubble diameter, bubble distribution, bubble aspect

20 ratio and the bubble rise velocity. The solids motion are investigated and compared on the basis of solids

21 circulation patterns and the magnitude of axial solids rise velocity. Definition of these parameters has

22 been discussed in section 5. Our discussion will be divided into a grid size dependency test presented in

23 Section 6.1, a comparison of simulation with experimental results to show reliability of the TFM in 
1 Section 6.2, and a detailed comparison of the effect of various configurations of vertical tubes in Section

26.3.

\section{$3 \quad$ 6.1. Grid independence test}

4 It is known that numerical solutions are grid dependent, where solutions obtained on grids that are too

5 coarse might not be accurate. Adequately refined grid simulations are required to obtain acceptable

6 solution accuracy. However, simulations on overly fine grids will require very small time steps that will

7 make them computationally too expensive for studying a large domain. The proper choice of grid size

8 should resolve gas-solids flow structures on the smallest relevant microscopic length and time scales [41].

9 Andrews et al. [42] reported that a grid size less than $10 \mathrm{dp}$ is required to capture the flow behavior

10 accurately. This shows that gas-solids flow simulations are sensitive to grid size-to-particle diameter ratio.

11 As a test of grid dependency, we performed the simulation for a triangular tube arrangement with grid

12 sizes of $1.5,2.0$ and $2.5 \mathrm{~mm}\left(5.2 \mathrm{~d}_{\mathrm{p}}, 7.0 \mathrm{~d}_{\mathrm{p}}\right.$ and $8.65 \mathrm{~d}_{\mathrm{p}}$ respectively). The grids were uniformly sized in all

13 three directions. Fig. 3 (a) and (b) compare equivalent bubble diameter and bubble rise velocity on

14 selected grid sizes. Fig. 3(a) shows that the equivalent bubble diameter predicted on coarse grid is slightly

15 larger than with the finer mesh. Similarly, an increase in bubble rise velocity is observed as the mesh is

16 coarsened in Fig. 3(b). This is caused by the fact that small bubbles (less than few grid sizes) are not well

17 resolved on the coarser grid. This is clear from Fig 4(a) where a more bubbles are predicted on fine grid

18 throughout the height of the bed and the number of small bubbles increases as the grid size is decreased

19 (Fig. 4(b)). We also found that excessive refinement leads to convergence difficulties; therefore the 20 uniform grid size of $1.5 \mathrm{~mm}\left(5.2 \mathrm{~d}_{\mathrm{p}}\right)$ is used for the remainder of this work.

\subsection{Comparison between simulations and experimental results}

22 In this section, we compare our simulation results with the experimental work of Rudisuli et al. [23].

23 Details on simulation settings and experimental conditions are given in Tables 2 and 3. Fig. 5 (a), (b) and

24 (c) show comparison of equivalent bubble diameter for inlet gas velocities of $\mathrm{U}_{0} / \mathrm{U}_{\mathrm{mf}}=2.3,4.5$ and 6.8 ,

25 respectively. In these figures, we will first focus on the experimental comparison for a bed without tubes.

26 For the bed without tubes, the simulation and experimental results are in good agreement for the higher 
inlet gas velocities of $\mathrm{U}_{0} / \mathrm{U}_{\mathrm{mf}}=4.5$ and 6.8 , except in the top section of the bed where bubble size

2 measured in the experiment is lower. This is the region of bubble eruption into the free board region,

3 where pressure fluctuation gives an artifact in bubble size due to bursting of bubble, as mentioned by

4 Rudisuli et al. [23]. The bubble size compared at $\mathrm{U}_{0} / \mathrm{U}_{\mathrm{mf}}=4.5$ and 6.8 (Fig. 5(b) and (c)) is in very good

5 agreement with the bubble size correlation from Werther [43]. For low inlet gas velocity of $\mathrm{U}_{0} / \mathrm{U}_{\mathrm{mf}}=2.3$

6 (Fig. 5(a)) simulation results show large differences, when compared with experimental measurements

7 and the literature correlation of Werther [43]. Where experimental results are under predicted and

8 literature correlation of Werther [43] shows slightly over predictions. Perhaps in the experiments,

9 pressure waves generated at the lower inlet gas velocity may not be strong enough to be detected

10 accurately by pressure sensors, resulting in inaccurate bubble size measurements. It explicitly depends

11 upon configuration/strength of pressure senor used; therefore more detail analysis of pressure fluctuation

12 measurement is required at low inlet gas velocity. Furthermore literature correlation of Werther [43] is

13 obtained from limited range of $\left(\mathrm{U}_{0}-\mathrm{U}_{\mathrm{mf}}\right)$ i.e. $0.05-0.30 \mathrm{~m} / \mathrm{s}$, therefore should be used with caution [40].

14 Considering the effect of in-bed vertical tubes in Fig. 5 (a), (b) and (c), a resultant reduction in bubble

15 size is observed for all three inlet gas velocities. Substantial reduction in bubble size is seen at the high

16 inlet gas velocity of $\mathrm{U}_{0} / \mathrm{U}_{\mathrm{mf}}=6.8$ (Fig. 5(c)). This shows that there is a significant influence of gas

17 velocity on the ability of vertical tubes to reduce bubble size. Qualitatively this is consistent with the

18 experimental results. Rudisuli et al. [23] observed the same bubble size for both square and triangular

19 tube arrangements; however simulations predict bubble sizes with a small sensitivity to the tube

20 arrangement. One potential reason for this difference is the fact that different methods were used to

21 determine bubble size in the simulations and experiments. We used a single vertical plane between the

22 tubes to determine bubble size, whereas pressure fluctuation measurements (PFM) in the experiments

23 give an averaged value over the full horizontal cross-sectional area. Also note that we did not take into

24 account the reduction area due to tubes, which can be another source of discrepancy. Nonetheless,

25 experimental results and simulation predictions are in fairly close agreement at higher inlet gas velocities

26 of $\mathrm{U}_{0} / \mathrm{U}_{\mathrm{mf}}=4.5$ and 6.8 . For low inlet gas velocity of $\mathrm{U}_{0} / \mathrm{U}_{\mathrm{mf}}=2.3$, the bubble size measurement from

27 experiments shows a lower trend, this behavior is due to the same reason as explained that the pressure

28 waves generated at the lower inlet gas velocity may not be strong enough to be detected accurately by 29 pressure sensors. 
2 In this section we focus on comparison of square and triangular tube arrangements. As a reference these

3 two tube configurations are also compared with bubbling bed without tubes with same operating 4 conditions.

\subsubsection{General bubble characteristics}

6 Fig. 6 shows instantaneous 3D bubble contours in a bed without and with vertical tubes. When there are 7 no vertical tubes, bubbles grow in size due to coalescence and move towards the center of the bed. In the 8 presence of vertical tubes, bubbles are comparatively smaller and distributed throughout the bed. As 9 discussed in the literature [8,44], vertical tubes prevent coalescence and promote bubble splitting. This phenomenon was observed in our simulation animations. Fig. 6 (b) and (c) show that bubbles take the

11 preferred path along the tubes. Actual calculations on bubble properties have been discussed in section 12 6.3.2. Fig. 7 shows time-averaged porosity plot within the measurement plane. This time-averaged porosity indicates the preferred bubble trajectories in the bed. The time-averaged porosity plot for the bed without tubes (Fig. 7 (a)) indicates that bubbles originate near the wall and move towards the center of the bed, probably driven by lower resistance offered in the center. For the bed with vertical tubes in (Fig. 7 (b) and (c)), higher void fraction is predicted along the tube, indicating rising bubbles in contact with the tubes. The trajectories of rising bubbles with and without vertical tubes are also measured by Ozawa et al. [44], and are consistent with our simulation results. Similarly, the time-averaged gas velocity magnitude

(Fig. 8) is predicted to be higher along the vertical tubes inside the bed. The variation in velocity with different tube arrangements can be seen in Fig. 8, where the square tube arrangement shows higher gas velocities in the measurement plane as compared to the triangular tube arrangement. At this stage, the argument could be that the rising bubble enclosed vertical tubes completely within the square

23 arrangement. The cross-sectional view of instantaneous gas volume fraction in Fig. 9 shows that vertical

24 tubes can be enclosed by larger bubble. We will discuss such observation in detail by comparing actual 25 bubble properties in the following sections. 
1 It is shown in Fig. 5 that both the square and the triangular tube arrangements act to reduce bubble size.

2 This reduction in bubble size is approximately 20,50 and 60\% for corresponding inlet gas velocities of $3 \mathrm{U}_{0} / \mathrm{U}_{\mathrm{mf}}=2.3,4.5$ and 6.8 , respectively. With vertical tubes, bubbles do not show significant growth as 4 they rise through vertical tubes, with the rate of growth being linear (See Fig. 5(a) and (b)). Fig. 10 shows 5 predicted bubble size as a function of lateral position averaged throughout the height of the bed. For a 6 given inlet gas velocity, the bubble size is larger in the center for a bed without tubes This results from the 7 bubbles forming at the bottom near the wall and then moving towards the bed center and coalescing as 8 they rise [45]. Vertical tubes prevent coalescence and promote bubble splitting. This is seen in Fig. 10 9 which shows an almost uniform average bubble size across the bed diameter as predicted by the model. 10 Splitting of bubble is evident from Fig. 11, where bubble distribution (calculated as the ratio of number of 11 bubble detected to the number of frame analyzed) is plotted as a function of axial position. For vertical 12 tube, a large number of bubbles are predicted throughout the height irrespective of inlet gas velocity. 13 Significantly more bubbles are predicted in the bottom section of the bed. This is due to the fact that U14 shape bank prevents bubble coalescence at the initial stage as the bubble grows. For inlet gas velocities of $15 \mathrm{U}_{0} / \mathrm{U}_{\mathrm{mf}}=2.3$ and 4.5 (Fig. 11 (a) and (b) respectively), a similar bubble distribution is predicted higher in 16 the bed, above $\mathrm{h}=0.25 \mathrm{~m}$, for both square and triangular tube arrangements. However, in the bottom 17 section of the bed (below $0.25 \mathrm{~m}$ ), the square tube arrangement predicts more bubbles. This shows that 18 the square tube arrangement is efficient in preventing coalescence of small bubbles in the lower bed 19 region, because the tubes create parallel chambers for the bubble to rise. At a higher gas velocity of $20 \mathrm{U}_{0} / \mathrm{U}_{\mathrm{mf}}=6.5$, (Fig. 11(c)) more bubbles are predicted for the triangular tube arrangement in the upper 21 section of the bed. This indicates that a triangular tube arrangement promotes bubble splitting due to the 22 staggered alignment of the tubes, compared to inline alignment in the square arrangement. This is also a 23 reason to observe lower average bubble size with triangular tube arrangement (See Fig. 5).

24 Yates et al. [20] claimed that at a certain distance from each other, vertical tubes break up bubbles into 25 daughter bubbles. Considering this phenomena, from Fig. 11(a) and (b) it can be seen that above the 26 height of $0.20 \mathrm{~m}$ larger bubbles split into two daughter bubbles for both tubes arrangements at low and 27 moderate inlet gas velocities. However, for the largest inlet gas velocity, Fig.11(c) shows that square 28 arrangement is effectively splitting bubble into two daughter bubbles and triangular arrangement into 
three. This further illustrates that the efficiency of vertical tube to split bubble not only depends on inlet

2 gas velocity but also on their arrangement.

3 Fig. 12 shows bubble distribution as a function of equivalent bubble diameter. In the model results, the

4 number of small bubbles in the bed is significantly greater for the beds with vertical tubes when compared

5 to the bed with no tubes. At a gas velocity of $\mathrm{U}_{0} / \mathrm{U}_{\mathrm{mf}}=6.8$ (Fig. 12(c)), the triangular tube arrangement

6 shows significantly more small bubbles due to splitting of larger bubbles; this result is consistent with

7 Fig. 11 (c). The number of larger bubbles is similar for both tube arrangements indicating that bubble

8 size is unaffected if it is sufficiently large compared to the tube spacing.

6.3.3. Bubble aspect ratio

Vertical tubes not only affect bubble size and bubble distribution, but also the bubble shape. The shape of

11 the bubble can be estimated from the bubble aspect ratio, defined as ratio of vertical length to the

12 horizontal length of the bubble. Fig. 13 shows bubble aspect ratio as a function of equivalent bubble

13 diameter. When there are no tubes, bubbles are nearly spherical in shape with a bubble aspect ratio close

14 to one but become slightly more elongated as the fluidization velocity increases. The presence of vertical

15 tubes shows a significant effect on the bubble shape over the range of inlet gas velocities modeled as seen

16 in Fig 13(a), (b) and (c). The larger bubble aspect ratio shows that bubbles elongate significantly under

17 the influence of vertical tubes. This is because the initial effect of vertical tubes is to squeeze and deform

18 bubbles to fit the space between the tubes. A similar observation on bubble shape impact is measured by

19 Asegehegn et al. [13] when they measured bubble properties between arrays of horizontal tubes. We have

20 not yet found experimental data available on the effect of vertical tubes on the bubble shape. The increase

21 in bubble aspect ratio is also attributed to splitting bubbles in horizontal direction by vertical tubes. This

22 splitting of bubble in horizontal direction reduces their horizontal length, resulting in larger bubble aspect

23 ratio. It is interesting to note that triangular tube arrangements shows considerable difference in bubble

24 shape factor when compared with square tube arrangement. The reason for this corresponds to the tube

25 alignment. The triangular tube arrangement occupies more number of principal tubes, thus creating

26 narrow spacing throughout the cross section. This narrow spacing split and squeezed bubble significantly

27 resulting in higher bubble aspect ratio. For inlet gas velocity of $\mathrm{U}_{0} / \mathrm{U}_{\mathrm{mf}}=6.8$ (Fig. 13(c)), same sized 
1 bubble have lower bubble aspect ratio i.e. bubble is less elongated, when compared to inlet gas velocity of

$2 \quad \mathrm{U}_{0} / \mathrm{U}_{\mathrm{mf}}=2.3$ (Fig. 13(a)). This is because at very high gas velocity bubbles are trapped and rise along the 3 tube.

4 Overall it can be concluded that the square tube arrangement prevents coalescence of small bubbles and

5 the triangular tube arrangement promotes splitting of large bubbles - depending on the fluidizing

6 velocities. If the bubble is larger than tube spacing, it encloses the vertical tube as it rises.

\section{$7 \quad$ 6.3.4. Bubble rise velocity}

8 The bubble rise velocity is an important property to characterize fluidization, as it directly influences the

9 bubble phase residence time. Grace and Harrison, [9] reported that vertical tubes significantly affect

10 bubble rise velocity. They concluded that bubbles travel faster when there are vertical tubes inside the

11 bed. Similarly references $[20,46]$ showed that bubble rise velocity increases with an increase in the

12 number of vertical tubes. Rudisuli et al. [11] found no clear trend in bubble rise velocities for vertical

13 tubes. They observed trends in bubble rise velocity for varying inlet gas velocity at two different heights

14 in the column. Since these findings are contrary to other literature studies, they suggested examining

15 thoroughly the effect of vertical tubes on bubble rise velocity. In this work we use simulations to

16 investigate the effect of vertical tubes on bubble rise velocity..

17 Fig. 14 shows average bubble rise velocity as a function of height from the bottom for different inlet gas

18 velocities. For low inlet gas velocities of $\mathrm{U}_{0} / \mathrm{U}_{\mathrm{mf}}=2.3$ and 4.5 i.e. in Fig. 14 (a) and (b), bubble rise

19 velocity shows an increasing trend in the presence of tubes, below the height of $0.3 \mathrm{~m}$. Above this height

20 bubble rise velocity is higher for bed without tubes. For inlet gas velocity of $U_{0} / U_{m f}=6.5$ i.e. Fig $14(c)$

21 shows that the bubble rise velocity is lower for the bed with the tubes, specifically above the height of

$220.10 \mathrm{~m}$. Rudisuli et al. [11] also studied trends in bubble rise velocity, depending upon gas flow rate and

23 height from the bottom. For a square tube arrangement at $\mathrm{U}_{0} / \mathrm{U}_{\mathrm{mf}}=2.3$, they found a decrease in bubble

24 rise velocity at height of $0.243 \mathrm{~m}$ and $0.45 \mathrm{~m}$ (note that they have only two measurement locations) 
compared to a bed without tubes. Our simulation results are consistent with their findings for an inlet gas

2 velocity of $\mathrm{U}_{0} / \mathrm{U}_{\mathrm{mf}}=2.3$. For $\mathrm{U}_{0} / \mathrm{U}_{\mathrm{mf}}=4.5$, Rudisuli et al. [11] found that bubble rise velocity increases at

3 both measured heights. Simulation results are consistent with their observation only for the height of

$4 \quad 0.245 \mathrm{~m}$. For $\mathrm{U}_{0} / \mathrm{U}_{\mathrm{mf}}=6.8$ they found bubble rise velocity decreases at $0.243 \mathrm{~m}$ and increase at $0.450 \mathrm{~m}$.

5 Simulation results are consistent at a height of 0.45 only. The possible discrepancy in the results could be

6 due to limitations of the optical probe measurement technique. The optical probe measurement gives only

7 local information depending upon the location of optical probe, whereas in our simulation we considered

8 averaging of all the bubbles at the given height, to determine average bubble rise velocity.

9 When comparing bubble rise velocity for square and triangular tube arrangement, the latter one shows 10 higher bubble rise velocity at $\mathrm{U}_{0} / \mathrm{U}_{\mathrm{mf}}=2.3$ and 4.5 , and lower at $\mathrm{U}_{0} / \mathrm{U}_{\mathrm{mf}}=6.5$. The potential reason is that 11 at low inlet gas velocities bubble size is comparable to the tube spacing, therefore considerable squeeze 12 occurs between the tubes and bubbles rise faster. At higher gas velocities, bubble sizes are large enough 13 that they enclose the tube and rise along the tube walls. Grace and Harrison, [9] claimed that if the ratio of 14 bubble size to tube diameter is greater than 5, several bubbles will enclose the vertical tube and rise along 15 their wall. In another work of Rudisuli et al. [11], faster bubble rise velocity was observed between the tubes as compared to velocities along the tube. As a result of the squeezing of bubble between the tubes, 17 the centroid of bubble moves a longer distance than uniform size bubble. Elongation of bubbles is 18 apparent in the bubble aspect ratio results shown in Fig. 13. For $\mathrm{U}_{0} / \mathrm{U}_{\mathrm{mf}}=6.5$, bubble rise velocity is 19 much higher in the bed without tubes because bubbles formed at a high inlet gas velocity are much larger 20 (see Fig. 5(c)) and are expected to rise faster.

21 Fig. 15 (a), (b) and (c) shows bubble rise velocity as a function of equivalent bubble diameter for inlet 22 gas velocities of $\mathrm{U}_{0} / \mathrm{U}_{\mathrm{mf}}=2.3,4.5$ and 6.8 respectively. These figures show that bubbles of the same size 23 rise with different velocities, where bubbles travel faster in the bed with tubes. The reason is given in the 24 literature $[9,46]$ : the bubble is elongated and follows preferential path along the vertical tubes. Yates et al. [20] indicates that bubble rise velocity can become twice as fast as bubble of the same volume in the 
1 absence of the tubes. Our simulation predicts this behavior for inlet gas velocity of $U_{0} / U_{m f}=2.3$ and

$2 \mathrm{U}_{0} / \mathrm{U}_{\mathrm{mf}}=4.5$. For $\mathrm{U}_{0} / \mathrm{U}_{\mathrm{mf}}=6.8$ bubble rise velocity is approximately $50 \%$ higher than in the absence of

3 tubes. This shows that bubble rise velocity in the bed with tubes depends upon fluidizing gas velocity.

4 The bubbles are rising relatively faster in the triangular tube arrangement. This observation is consistent

5 with Fig. 13 (a) and (b).

\section{$6 \quad$ 6.3.5. Solids flow characteristics}

7 Solids circulation pattern in the bubbling bed is another important factor which affects the fluidization

8 quality. Solids particles are dragged up by the bubbles in their wakes and, by continuity particle will

9 move downwards in the regions with no or few bubbles. Researchers [1, 39, 47] have investigated

10 extensively the solid circulation patterns for bubbling beds without tubes. The impact of horizontal tubes

11 on solids circulation pattern have been investigated [24], but to our knowledge no investigations of solids

12 circulations for in-bed vertical tubes have been reported. Rudisuli el al. (2012a) [11] proposed a

13 description of solid motion/circulation from analogy of bubble motion for the bed with vertical tubes.

14 However actual validation or confirmation on the solids motion in the bed with vertical tubes has not been

15 reported. Therefore it becomes of practical importance to investigate fluidized bed solids motion as

16 affected by vertical tubes. Fig. 16 (a), (b) and (c) show time-averaged solids circulation patter within the

17 measurement plan for $\mathrm{U}_{0} / \mathrm{U}_{\mathrm{mf}}=4.5$ representing bed without tube, square and triangular arrangement

18 respectively. For clarity only reasonable numbers of vectors are shown, and lateral and axial lengths in

19 these figures are on different scale. For the triangular tube arrangement in Fig. 16(c), velocity vectors in

20 the region $\mathrm{x}>0.12 \mathrm{~m}$ are ignored due to clustering of surrounding tubes in that region. Note that vertical

21 dotted line in these figures represent the location of vertical tubes, where magenta colored line represent

22 tubes located on the other side of the measurement plane. Fig. 16(a) shows that in the absence of tubes,

23 solids circulation forms distinct vortices within the bed. In the bottom section of the bed below $0.1 \mathrm{~m}$,

24 solids are descending in the center and ascending near to the wall. The predicted behavior above the 
1 height of $0.1 \mathrm{~m}$ shows the opposite trend. Solids circulation zones are formed in the middle and top of the

2 bed, with dominant upward solids motion in the bed center. High velocity solids at the bed surface

3 indicate the splashing of particles into the freeboard region due to abrupt eruption of the bubble. These

4 predictions are consistent with the literature [1, 47]. In the bed with vertical tubes (Fig. 16 (b) and (c)),

5 this splashing of solids into freeboard regions is gentle, due to vertical tubes promoting bubble eruption

6 phenomena to occur slowly. Solids circulation patterns in the bed with vertical tubes are different

7 compared to beds without tubes, especially in the bottom section of the bed. In the bottom section of the

8 bed, solids circulation vortices disappear and solids move upward in the center. This is due to presence of

9 U-shape banks, preventing solid circulation. Elongated solids circulation vortices are formed due to

10 vertical tubes, with solids rising along the tubes. Fig. 16(b) indicates that solids are circulating in small,

11 parallel compartments for the square tube arrangement, whereas in the triangular arrangement these

12 circulating zones are missing (Fig. 16(c)). Radial motion of particles is less pronounced for vertical tubes,

13 preventing radial mixing. Authors $[8,44]$ also claimed that vertical tubes did not allow radial mixing in

14 fluidized beds. For vertical tubes, solids are continuously descending near the wall of the fluidized bed.

15 Very similar solids flow patterns are seen for inlet gas velocities of $\mathrm{U}_{0} / \mathrm{U}_{\mathrm{mf}}=2.3$ and 6.8 (Figures not 16 shown).

17 Fig. 17 and 18 (a), (b) and (c) show the magnitude of axial solids velocity at heights of $0.18,0.34$ and

$180.51 \mathrm{~m}$ from the bottom at fluidizing velocities of $\mathrm{U}_{0} / \mathrm{U}_{\mathrm{mf}}=2.3$ and 4.5 . A clear trend for the bed without

19 tubes is seen with high solids velocity in the bed center and low solids velocity away from the bed center

20 at all the reported heights. At the reported bed heights, downward motion of solids takes place near the

21 walls. Fig. 17(b) and 18(b) show the solids axial velocity profile for the square tube arrangement, where

22 higher solids velocities lie in the region between the tubes. This shows that collections of 4 tubes (i.e. the

23 square arrangement) form a column of solids that act as a separate, small 3D bed. Descending of particles

24 is seen near the bed walls due to more free space available due to the presence of only auxiliary tube of

25 relatively small tube diameter (see Table 3). For the triangular tube arrangement data shown in Fig. 17(c), 
1 zig-zag motion of solids is predicted, rising high in the region formed by the triangular vertical tube

2 arrangement. The magnitude of solids velocities is nearly the same at these three heights for vertical

3 tubes. Experimental work would be very valuable to investigate solids velocities for in-bed vertical tubes

4 and useful to validate the simulations. Nevertheless simulations results provide an understanding on

5 solids motion.

\section{$6 \quad$ 7. Conclusions}

7 The influence of vertical tubes on bubble characteristics and solids motion in a fluidized bed has been

8 investigated using the MFIX two-fluid model. Square and triangular tube arrangements have been

9 compared to the bed without tubes for a range of inlet gas velocities of $\mathrm{U}_{0} / \mathrm{U}_{\mathrm{mf}}=2.3,4.5$ and 6.8 . The

10 vertical tubes influence the hydrodynamics of fluidized beds significantly. A decrease in equivalent

11 bubble diameter and a uniform distribution of bubble are seen for the bed with vertical tubes at all three

12 inlet gas flow conditions. A considerable reduction in bubble sizes is seen for in-bed vertical tubes at

$13 \mathrm{U}_{0} / \mathrm{U}_{\mathrm{mf}}=6.8$. Simulation results show that the square tube arrangement forms longitudinal, parallel

14 chambers that prevent bubble coalescence. Since triangular tubes are in a staggered arrangement, they

15 promote bubble splitting. Due to splitting and squeezing of bubbles between the tubes their shapes change

16 significantly, becoming more elongated. The elongated bubble of the same size has a higher bubble rise

17 velocity in the bed with the vertical tubes. Differences in solids circulation patterns are very distinct for

18 the three bed configurations. Solids circulating zones are predicted for the square arrangement, whereas

19 circulating zones are not seen for the triangular tube arrangement. Significant solids motion is rarely seen

20 in the radial direction because the vertical tubes prevent lateral solids motion. Higher axial solid velocity

21 is predicted in the center for the bed without tubes whereas the beds with tubes show higher axial velocity

22 between the tubes. This indicates that vertical tubes divide the bed into smaller, parallel chambers for gas-

23 solids to flow. Therefore, use of vertical tubes in fluidized beds show an advantage for bed scale up. 
1 A comparison of simulation results with experimental data shows good agreement. Evaluations of various

2 bubble characteristics are consistent with results reported in the literature. Further experimental work is

3 important for further validation of simulation result and to improve understanding of solids motion in the

4 presence of the vertical tubes. Nevertheless this study provides valuable insight into bubble and solids

5 behavior and the effects of in-bed, vertical tubes.

\section{Nomenclature}

$7 \mathrm{~g} \quad$ gravitational acceleration, $\left[\mathrm{m} / \mathrm{s}^{2}\right]$

$8 \quad \mathrm{~g}_{0} \quad$ radial distribution function, [-]

$9 \quad d_{p} \quad$ diameter of particle, $[\mathrm{m}]$

$10 \mathrm{p}$ pressure, $[\mathrm{Pa}]$

$11 \mathrm{v} \quad$ velocity $[\mathrm{m} / \mathrm{s}]$

$12 \mathrm{t}$ time, [s]

$13 e_{p p} \quad$ coefficient of restitutions, [-]

$14 \mathrm{U}_{\mathrm{mf}}$ minimum fluidization velocity, $[\mathrm{m} / \mathrm{s}$ ]

$15 \mathrm{U}_{0} \quad$ superficial velocity, $[\mathrm{m} / \mathrm{s}]$

$16 \mathrm{~N}_{\mathrm{b}} \quad$ Number of bubbles

$17 \quad A_{b} \quad$ Area occupied by the bubble

18 Greek symbols

$19 \phi \quad$ volume fraction, [-]

$20 \rho \quad$ density, $\left[\mathrm{kg} / \mathrm{m}^{3}\right]$

$21 \theta \quad$ pseudo particles temperature, $\left[\mathrm{m}^{2} / \mathrm{s}^{2}\right]$

$22 \tau \quad$ stress tensor, $[\mathrm{Pa}]$

23 Subscripts/Superscript

24 s solid phase 


$$
\begin{array}{lll}
1 & \mathrm{~g} & \text { gas phase } \\
2 & \mathrm{p} & \text { particle } \\
3 & \mathrm{mf} & \text { minimum fluidization } \\
4 & \mathrm{~b} & \text { bubble } \\
5 & \text { avg } & \text { averaged quantity }
\end{array}
$$

\section{Acknowledgements}

7 This technical effort was performed in support of the U.S. Department of Energy, Office of Fossil

8 Energy's Carbon Capture Simulation Initiative (CCSI) through the National Energy Technology

9 Laboratory under the RES contract DE-FE0004000. This research was also supported in part by an

10 appointment to the National Energy Technology Laboratory Research Participation Program, sponsored

11 by the U.S. Department of Energy and administered by the Oak Ridge Institute for Science and

12 Education.

\section{Disclaimer}

14 This report was prepared as an account of work sponsored by an agency of the United States Government.

15 Neither the United States Government nor any agency thereof, nor any of their employees, makes any 16 warranty, express or implied, or assumes any legal liability or responsibility for the accuracy, 17 completeness, or usefulness of any information, apparatus, product, or process disclosed, or represents 18 that its use would not infringe privately owned rights. Reference herein to any specific commercial 19 product, process, or service by trade name, trademark, manufacturer, or otherwise does not necessarily 20 constitute or imply its endorsement, recommendation, or favoring by the United States Government or 21 any agency thereof. The views and opinions of authors expressed herein do not necessarily state or reflect 22 those of the United States Government or any agency thereof.

\section{References}


1 [1] J.A. Laverman, X. Fan, A. Ingram,, M. van Sint Annaland, D.J. Parker, J.P.K. Seville, J.A.M.

2 Kuipers, Experimental study on the influence of bed material on the scaling of solids circulation

3 patterns in 3D bubbling gas-solid fluidized beds of glass and polyethylene using positron emission

$4 \quad$ particle tracking, Powder Technol. 224 (2012) 297-305.

5 [2] G.C. Brouwer, E.C. Wagner, J.R. van Ommen, R.F. Mudde, Effects of pressure and fines content on 6 bubble diameter in a fluidized bed studied using fast X-ray tomography, Chem. Eng. J. 207-208 $7 \quad$ (2012) $711-717$.

8 [3] C. Rautenbach, R.F. Mudde, X. Yang, M.C. Melaaen, B.M. Halvorsen, A comparative study between 9 electrical capacitance tomography and time-resolved X-ray tomography, Flow Measurement and 10 Instrumentation. 30 (2013) 34-44.

11 [4] H. Lindborg, M. Lysberg, H.A. Jakobsen, Practical validation of the two-fluid model applied to dense 12 gas-solid flow in fluidized beds, Chem. Eng. Sci. 62(2007) 5854-5869.

13 [5] L. Cammarata, P. Lettieri, G. Micale, D. Colman, 2D and 3D CFD simulations of bubbling fluidized 14 beds using Eulerian-Eulerian models, IJCRE. 1 (2003) 1-19.

15 [6] A. Acosta-Iborra, C. Sobrino, F. Hernandez-Jimenez, M. deVega, Experimental and computational study on the bubble behavior in a 3-D fluidized bed, Chem. Engi. Sci. 66(2011) 3499-3512.

17 [7] A.E. Almsedt, Measurements of bubble behavior in a pressurized fluidized bed buring coal, using capacitance probes-Part II, Proceedings of 8th International Conference on Fluidized bed combustion. Houston. (1985) 865-877.

20 [8] Y. Jin, F. Wei, Y. Wang, Effect of internal tubes and baffles. In: Yang, W.-c. (Ed.), Handbook of 21 Fluidization and Fluid-Particle Systems, Marcel Dekker Inc., New York (2003). 
1 [9] J.R. Grace, D. Harrison, The effect of Internal baffles in fluidised beds: A guide to design, Inst. Chem. $2 \quad$ Symp. Ser. 27 (1968) 93-100.

3 [10] M.J. Lorences, J.P. Laviolette, G.S. Patience, M. Alonso, F.V. Diez, Fluid bed gas RTD: Effect of 4 fines and internals. Powder Technol. 168(2006) 1-9.

5 [11] M. Rudisuli, T.J Schildhauer, S.M.A. Biollaz, J.R. van Ommen, Radial bubble distribution in a $6 \quad$ fluidized bed with vertical tubes, Ind. Eng. Chem. Res. 51(2012) 13815-13824.

7 [12] T.M. Knowlton, S.B.R. Karri, A. Issangya, Scale-up of fluidized bed hydrodynamics, Powder $8 \quad$ Technol. 150(2005) 72-77.

9 [13] T.W. Asegehegn, M. Schreiber, H.J. Krautz, Influence of two- and three- dimensional simulations on 10 bubble behavior in gas-solid fluidized beds with and without immersed horizontal tubes, Powder 11 Tech. 219(2012) 9-19.

12 [14] O. Sitnai, A.B. Whitehead, Immersed tubes and other internals. In: Davidson, J.F., Clift, R., 13 Harrison, D. (Eds.), Fluidization, Academic Press, London (1985).

14 [15] A.S. Hull, Z. Chen, J.W. Fritz, P.K. Agarwal, Influence of horizontal tube banks on the behavior of 15 bubbling fluidized beds: 1. Bubble hydrodynamics, Powder Technol. 103-3(1999) 230-242.

16 [16] S.W. Kim, J.Y. Ahn, S.D. Kim, D. H. Lee, Heat transfer and bubble characteristics in a fluidized bed 17 with immersed horizontal tube bundle, Int. J. Heat Mass Transfer 46 (3) (2003), 399-409.

18 [17] P.A. Olowson, Influence of pressure and fluidization velocity on the hydrodynamics of a fluidized 19 bed containing horizontal tubes, Chem. Eng. Sci. 49 (15) (1994) 2437-2446. 
1

2

3

4

5

6

7

[18] S.E. Olsson, J. Wiman, A.E. Almstedt, Hydrodynamics of a pressurized fluidized bed with horizontal tubes: influence of pressure, fluidization velocity and tube-bank geometry, Chem. Eng. Sci. 50 (4) (1995) 581-592.

[19] J. Wiman, A.E. Almstedt, Hydrodynamics, erosion and heat transfer in a pressurized fluidized bed: influence of pressure, fluidization velocity, particle size and tube bank geometry, Chem. Eng. Sci. 52 (16) (1997) 2677-2695.

[20] J.G. Yates, R.S. Ruiz-Martinez, Interaction between horizontal tubes and gas bubbles in fluidized bed, Chem Eng. Comm 62(1987) 67-78.

[21] S. Ramamoorthy, N. Subramanian, Axial solids mixing and bubble characteristics in gas-fluidized beds with vertical internals, Chem. Eng. J. 22 (1981) 237-242.

[22] W. Volk, C.A. Johnson, H.H. Stotler, Effect of reactor internals on quality of fluidization, Chem. Eng. Prog. 58 (1962) 44-47.

[23] M. Rudisuli, T.J. Schildhauer, S.M.A. Biollaz, J.R. van Ommen, Bubble characterization in a fluidized bed with vertical tubes. Ind. Eng. Chem. Res. 51(2012) 4748-4758.

[24] H. Yurong, L. Huilin, S. Qiaoqun, Y. Lidan, Z. Yunhua, D. Gidaspow, J. Bouillard, Hydrodynamics of gas-solid flow around immersed tubes in bubbling fluidized beds, Powder Technol. 145 (2004) $88-105$.

[25] Y.Z. Zhao, M.Q. Jiang, Y.L. Liu, J.Y. Zheng, Particle-scale simulation of the flow and heat transfer behaviors in fluidized bed with immersed tube, AIChE J. 55 (12) (2009) 3109-3124.

[26] D. Rong, T. Mikami, M. Horio, Particle and bubble movements around tubes immersed in fluidized beds—a numerical study, Chem. Eng. Sci. 54 (23) (1999), 5737-5754. 
1 [27] T. Li, J.F. Dietiker, Y. Zhang, M. Shahnam, Cartesian grid simulations of bubbling fluidized bed 2 with a horizontal tube bundle, Chem. Eng. Sci. 8 (2011) 6220-6231.

3 [28] J.F. Dietiker, C. Guenther, M. Syamlal, A Cartesian cut cell method for gas/ solids flows, AIChE $4 \quad$ Annual Meeting. Nashville, TN (2009).

5 [29] J.F. Dietiker, https://mfix.netl.doe.gov, MFIX: Cartesian Grid User Guide, Morgantown. (2015).

6 [30] J. Ding, D. Gidaspow, A bubbling fluidization model using kinetic theory of granular flow, AIChE $7 \quad$ J. $36(1990) 523-538$.

8 [31] D. Gidaspow, Multiphase Flow and Fluidization: Continuum and Kinetic Theory Description, $9 \quad$ Academic Press Boston. (1994).

10 [32] A. Bakshi, C. Altantzis, A.F. Ghoniem, Towards accurate three-dimensional simulation of dense 11 multi-phase flows using cylindrical coordinates, Powder Technol. (2014) 242-255.

12 [33] J.F. Dietiker, T. Li, R. Garg, M. Shahnam, Cartesian grid simulations of gas-solids flow systems with complex geometry, Powder Techno. 235 (2013), 696-705.

14 [34] S. Benyahia, M. Syamlal, T.J. O’Brien, Summary of MFIX Equations 2012-1", From URL 15 https://mfix.netl.doe.gov/documentation/MFIXEquations 2012-1.pdf, (2012).

[35] M. Syamlal, MFIX Documentation: Numerical Techniques. (1998).

17 [36] M. Syamlal, W. Rogers, T.J. O’Brien, MFIX Documentation: Theory Guide. (1993).

18 [37] M.P. Kirkpatrick, S.W. Armfield, J.H. Kent, A representation of curved boundaries for the solution 19 of the Navier-Stokes equations on a staggered three-dimensional Cartesian grid, J. Comput. Phys. 184 (1) (2003) 1-36. 
1 [38] J.A.M. Kuipers, W. Prins, W.P.M. van Swaaij, Theoretical and experimental bubble formation at a 2 single orifice in a two-dimensional gas-fluidized bed. Chem. Eng. Sci. 46 (1991) 2881-2894.

3 [39] V. Verma, J.T. Padding, Deen N.G., J.A.M. Kuipers, Effect of bed size on hydrodynamics in 3-D $4 \quad$ gas-solid fluidized beds. AIChE J. 61(2015) 4.

5 [40] M. Rudisuli, T.J. Schildhauer, S.M.A. Biollaz, A Wokaun, J.R. van Ommen, Comparison of bubble 6 growth obtained from pressure fluctuation measurements to optical probing and literature 7 correlations. Chem. Eng. Sci. 74(2012) 266-275. [41] C. Guenther, M. Syamlal, The effect of 8 numerical diffusion on simulation of isolated bubbles in a gas-solid fluidized bed. Powder Tech. 116 $9 \quad$ (2001) $142-154$.

10 [42] A.T. Andrews, P.N. Loezos, S. Sundaresan, Coarse-grid simulation of gas-particle flows in vertical 11 risers. Ind. Eng. Chem. Res. 44 (2005) 6022-6037.

12 [43] J. Werther, Bubble growth in a large diameter fluidized beds, Int.Fluidization conference, Pacific 13 Grove, USA, 1975, in: D.L, Keairns (Ed.), Fluidization Technology, Hemisphere Publ. Co., 14 Washington DC, 1976, (1975). 215-235.

15 [44] M. Ozawa, H. Umekawa, S. Furui, K. Hayashi, N. Takenaka, Bubble behavior and void fraction 16 fluctuation in vertical tube banks immersed in a gas-solid fluidized-bed model. Exp. Thermal and $17 \quad$ Fluid Sci. $26(2002)$ 643-652.

[45] D. Kunii, O. Levenspiel, Fluidization Engineering, 2nd edition. Butterworth-Heinemann, Inc. 19 (1991).

[46] K. Gallucci, N. Jand, P.U. Foscolo, M. Santini, Cold model characterisation of a fluidised bed catalytic reactor by means of instantaneous pressure measurements, Chem. Eng. J. 87 (2002) 61-71. 
1 [47] M. Askarishahi, M-S. Salehi, H. R. Godini, G. Wozny, CFD study on solids flow pattern and solids

12 Table 1: Summary of TFM governing equations.

\section{Continuity equation:}

$\frac{\partial\left(\phi_{g} \rho_{g}\right)}{\partial t}+\nabla \cdot\left(\phi_{g} \rho_{g} \stackrel{\mathbf{r}}{v_{g}}\right)=0$

$\frac{\partial\left(\phi_{s} \rho_{s}\right)}{\partial t}+\nabla \cdot\left(\phi_{s} \rho_{s} \hat{v}_{s}\right)=0$

Momentum equation:

$$
\begin{aligned}
& \frac{\partial\left(\phi_{g} \rho_{g} \dot{v}_{g}\right)}{\partial t}+\nabla \cdot\left(\phi_{g} \rho_{g} \underset{v_{g}}{\mathbf{r}} \underset{v_{g}}{\mathbf{r}}\right)=-\phi_{g} \nabla p_{g}-\nabla \cdot\left(\phi_{g} \overline{\bar{\tau}}_{g}\right)-\beta_{g \cdot s}\left(\underset{v_{g}}{\mathbf{r}}-\underset{v_{s}}{\mathbf{r}}\right)+\phi_{g} \rho_{g} \underset{g}{\mathbf{r}} \\
& \frac{\partial\left(\phi_{s} \rho_{s} \dot{v}_{s}\right)}{\partial t}+\nabla \cdot\left(\phi_{s} \rho_{s} \underset{v_{s}}{\mathbf{r}} v_{s}\right)=-\phi_{s} \nabla p_{g}-\nabla p_{s}-\nabla \cdot\left(\phi_{s} \overline{\bar{\tau}}_{s}\right)+\beta_{g \cdot s}\left(\underset{v_{g}}{\mathbf{r}}-\underset{v_{s}}{\mathbf{r}}\right)+\phi_{s} \rho_{s} \underset{g}{\mathbf{r}}
\end{aligned}
$$

Granular energy conservation (algebraic formulation):

$\theta_{s}=\left[\frac{-K_{1} \phi_{s} t r\left(D_{s}\right)+\sqrt{\left[K_{1} t r\left(D_{s}\right) \phi_{s}\right]^{2}+4 K_{4} \phi_{s}\left[K_{2} t r^{2}\left(D_{s}\right)+2 K 3\left(D_{s}: D_{s}\right)\right]}}{2 \phi_{s} K_{4}}\right]^{2}$

Where $D_{s}=\frac{1}{2}\left[\nabla v_{s}^{\mathbf{r}}+\left(\nabla v_{s}\right)^{T}\right]$ 


$$
\begin{aligned}
& K_{1}=2\left(1+e_{p p}\right) \rho_{s} g_{0}, \quad K_{2}=\frac{4 d_{p}\left(1+e_{p p}\right) \rho_{s} \phi_{s} g_{0}}{3 \sqrt{\pi}}-\frac{2}{3} K_{3}, \\
& K_{3}=\frac{d_{p} \rho_{s}}{2}\left\{\frac{\sqrt{\pi}}{3\left(3-e_{p p}\right)}\left[0.5\left(1+3 e_{p p}\right)+0.4\left(1+3 e_{p p}\right)\left(3 e_{p p}-1\right) \phi_{s} g_{0}\right]+\frac{8 \phi_{s} g_{0}\left(1+e_{p p}\right)}{5 \sqrt{\pi}}\right\}, \\
& K_{4}=\frac{12\left(1-e_{p p}^{2}\right) \rho_{s} g_{0}}{d_{p} \sqrt{\pi}}
\end{aligned}
$$

\section{Gidaspow drag correlation:}

$$
\begin{aligned}
& \beta_{g \cdot s}= \begin{cases}\frac{3}{4} C_{D} \frac{\rho_{g} \phi_{g} \phi_{s}\left|v_{g}-v_{s}\right|}{d_{p}} \phi_{s}^{-2.65} & \phi_{g} \geq 0.8 \\
\frac{150 \phi_{s}\left(1-\phi_{g}\right) \mu_{g}}{\phi_{g} d_{p}^{2}}+\frac{1.75 \rho_{g} \phi_{s}\left|v_{g}-v_{s}\right|}{d_{p}} & \phi_{g}<0.8\end{cases} \\
& C_{D}= \begin{cases}\frac{24}{\operatorname{Re}\left(1+0.15 \mathrm{Re}^{0.687}\right)} & \operatorname{Re}<1000 \\
0.44 & \operatorname{Re} \geq 1000\end{cases} \\
& \operatorname{Re}=\frac{\rho_{g} \varphi_{g}\left|v_{g}-v_{s}\right| d_{p}}{\mu_{g}}
\end{aligned}
$$

Table 2: Material properties and operating conditions for the TFM simulation

\section{Properties}

Particle type

Particle density

Particle diameter

Coefficient of restitution

Minimum fluidizing velocity $\left(\mathrm{U}_{\mathrm{mf}}\right)$

Superficial velocity at inlet $\left(\mathrm{U}_{0}\right)$

\section{Values}

Aluminum oxide

$1350 \mathrm{~kg} / \mathrm{m}^{3}$

$289 \mu \mathrm{m}$

0.90

$0.041 \mathrm{~m} / \mathrm{s}$

$2.3 \mathrm{U}_{\mathrm{mf}}, 4.5 \mathrm{U}_{\mathrm{mf}}, 6.8 \mathrm{U}_{\mathrm{mf}}$
8

9

10

11

12

Table 3: geometry and grid specification in the simulations

\begin{tabular}{lccc}
\hline Properties & Without tubes & Sq. arrangement & Tri. arrangement \\
Column width (number of grids) & $0.15 \mathrm{~m}(100)$ & $0.15 \mathrm{~m}(100)$ & $0.15 \mathrm{~m}(100)$ \\
Column depth (number of grids) & $0.15 \mathrm{~m}(100)$ & $0.15 \mathrm{~m}(100)$ & $0.15 \mathrm{~m}(100)$ \\
Column height (number of grids) & $0.96 \mathrm{~m}(640)$ & $0.96 \mathrm{~m}(640)$ & $0.96 \mathrm{~m}(640)$ \\
\hline
\end{tabular}




\begin{tabular}{llll}
\hline Bed diameter from cut-cells & $0.145 \mathrm{~m}$ & $0.145 \mathrm{~m}$ & 0.145 \\
Initial solid bed height & $0.50 \mathrm{~m}$ & $0.50 \mathrm{~m}$ & $0.50 \mathrm{~m}$ \\
Initial solid volume fraction & 0.58 & 0.58 & 0.58 \\
& & & \\
Number of principal tubes (diameter) & - & $16(15 \mathrm{~mm})$ & $24(15 \mathrm{~mm})$ \\
Number of auxiliary tubes (diameter) & - & & $2(10 \mathrm{~mm})$
\end{tabular}

1

2

3

4

5

6

7

8

9

10

11

12

13

a

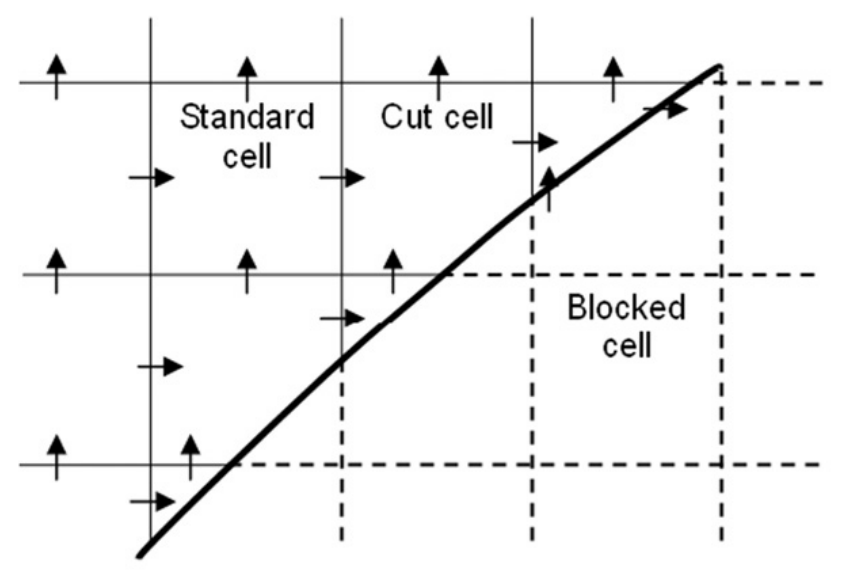

b

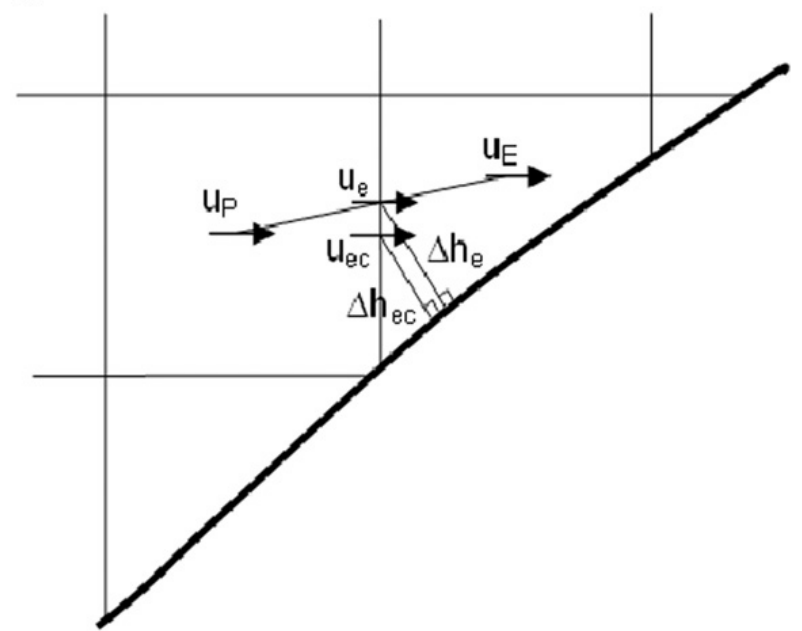

15 Fig. 1. Cut cell treatment on a staggered grid, (a) Scalar cut-cells with location of velocity nodes, (b)

16 interpolation of velocity at the face of cut-cell. 

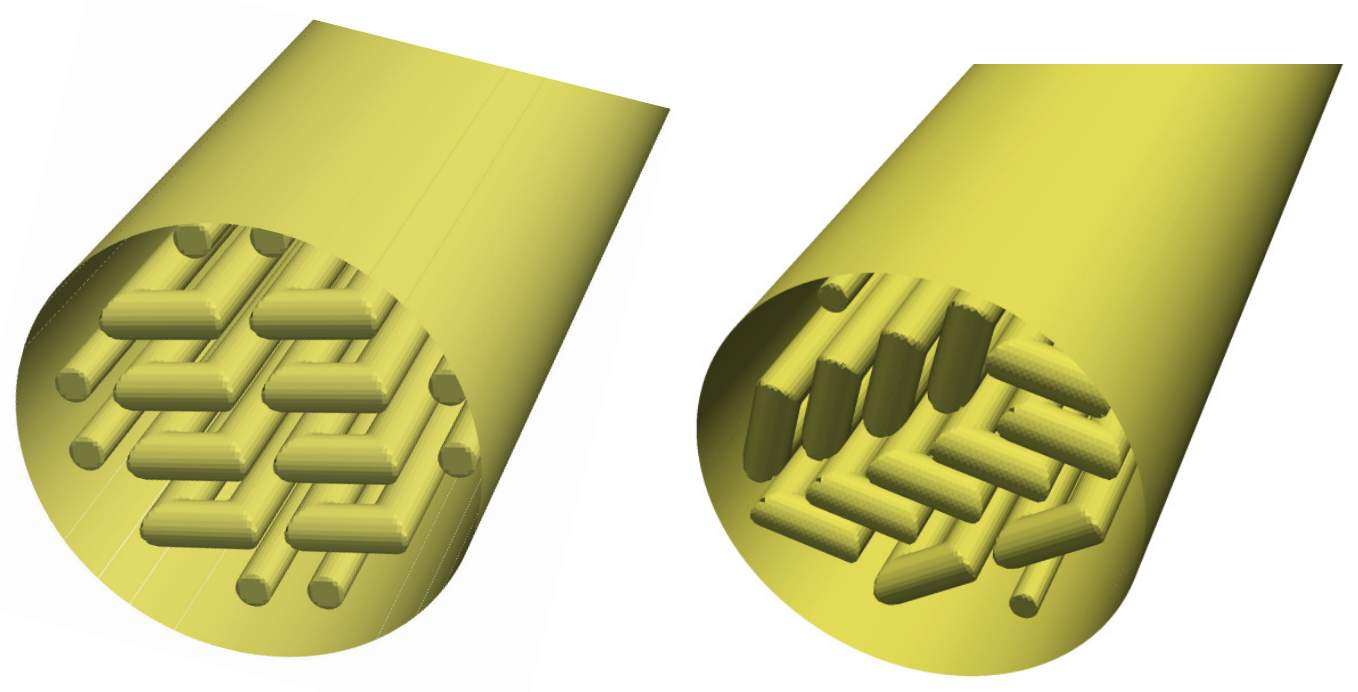

2

3

(a)

(b)

4 Fig. 2. 3D view of the column with vertical tube inside having (a) square tube arrangement and, (b)

5 triangular tube arrangement.

6

7

8

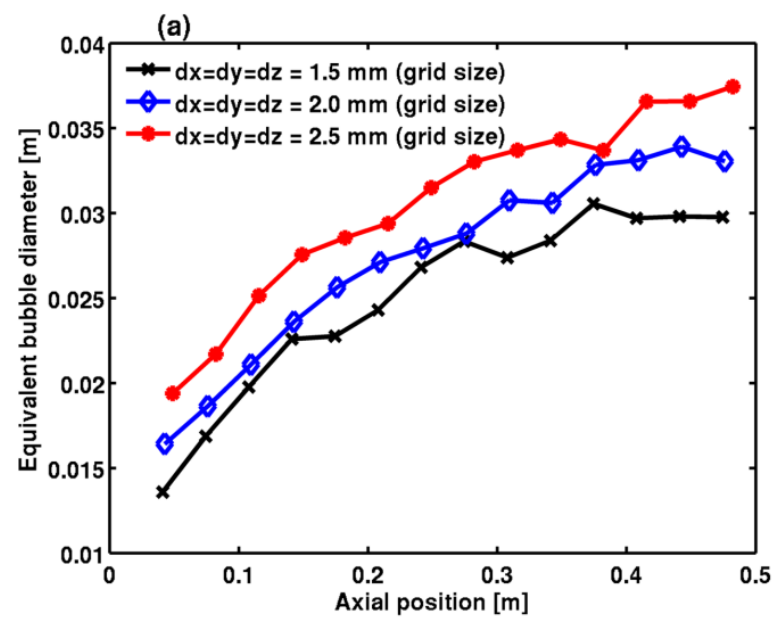




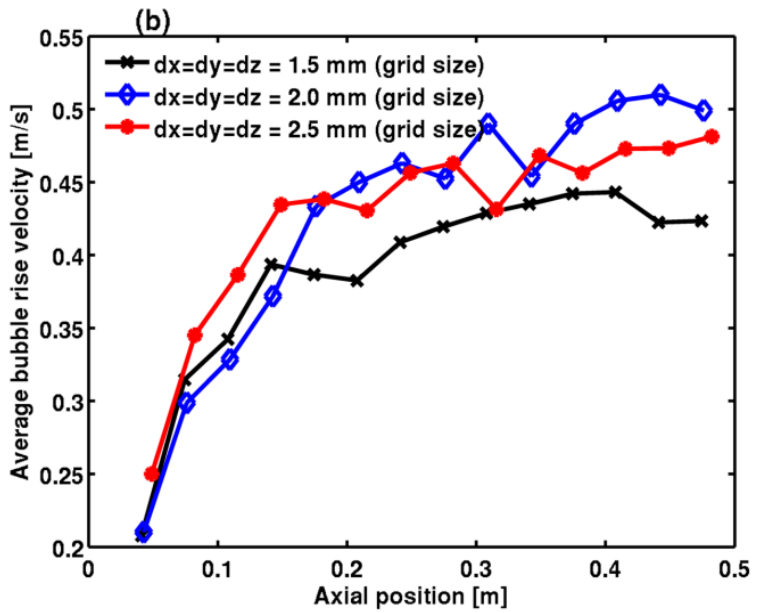

3 Fig. 3. Effect of grid size on (a) the equivalent bubble diameter, and (b) the bubble rise velocity, at 4 different height from the bottom in the bed with triangular tube arrangement for $\mathrm{U}_{0} / \mathrm{U}_{\mathrm{mf}}=4.5$.

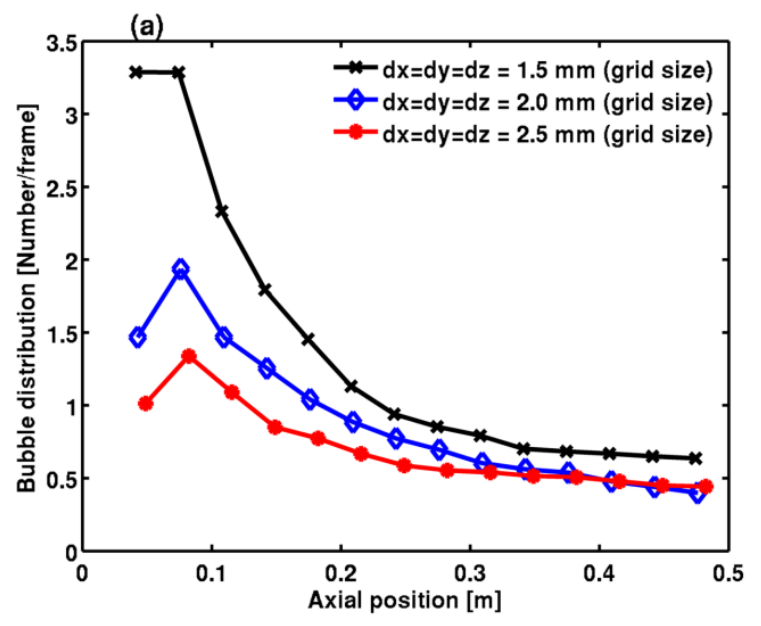




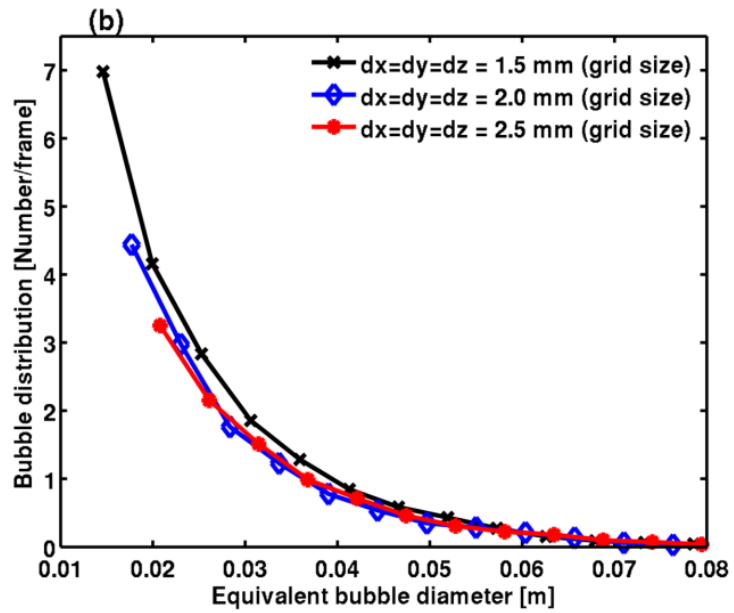

3 Fig. 4. Effect of grid size on bubble distribution as a function of (a) height from the bottom, and (b) the 4 equivalent bubble diameter, for the bed with triangular tube arrangement operating at $\mathrm{U}_{0} / \mathrm{U}_{\mathrm{mf}}=4.5$.

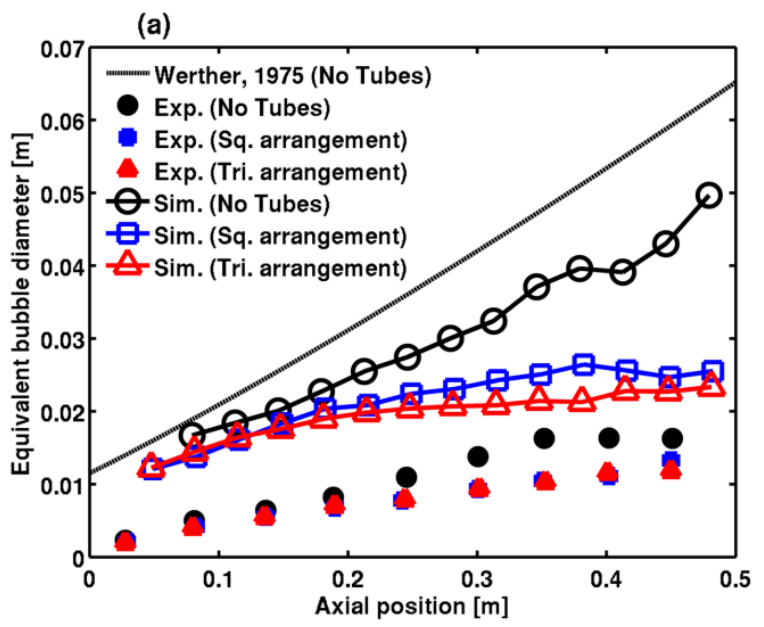



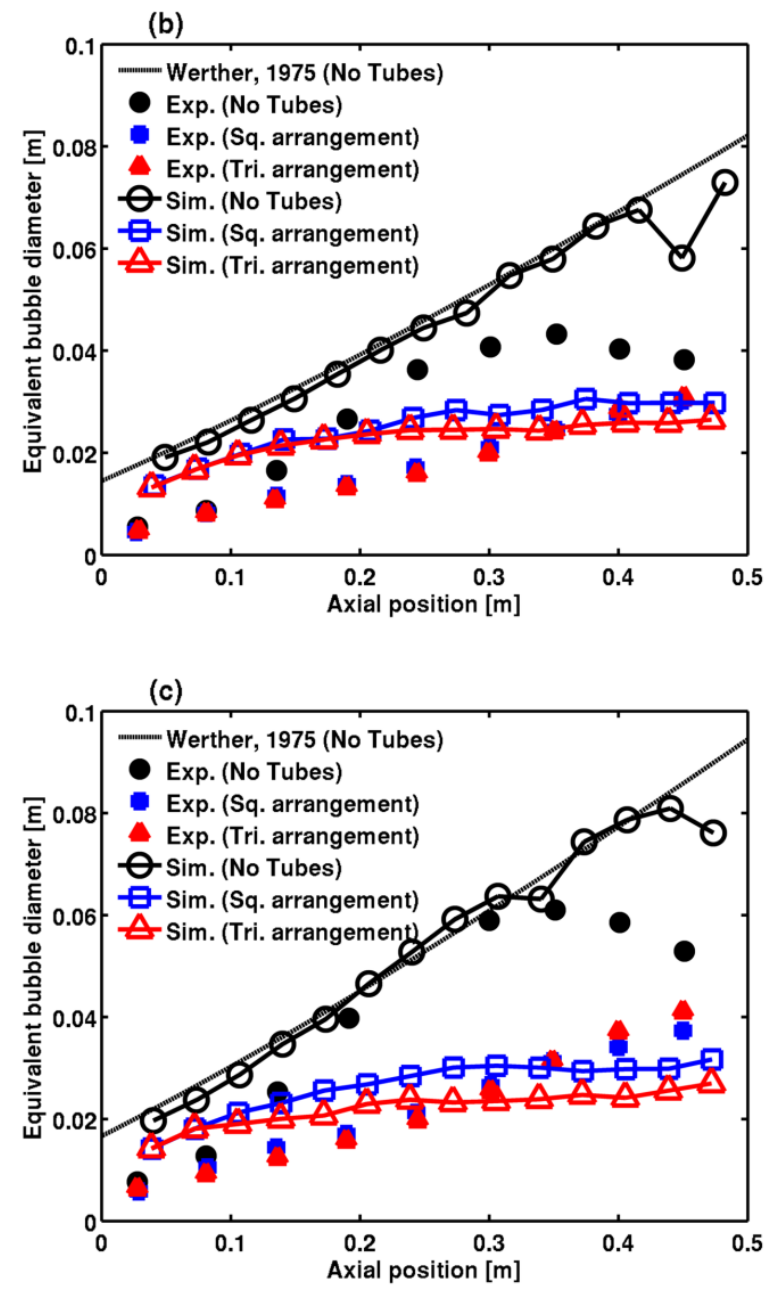

3 Fig. 5. Equivalent bubble diameter as a function of height from the bottom comparing bed with and

4 without tubes at operating inlet gas velocity of (a) $\mathrm{U}_{0} / \mathrm{U}_{\mathrm{mf}}=2.3$, (b) $\mathrm{U}_{0} / \mathrm{U}_{\mathrm{mf}}=4.5$, and (c) $\mathrm{U}_{0} / \mathrm{U}_{\mathrm{mf}}=6.8$,

5 comparison with experimental results of Rudisuli et al. [23]. 


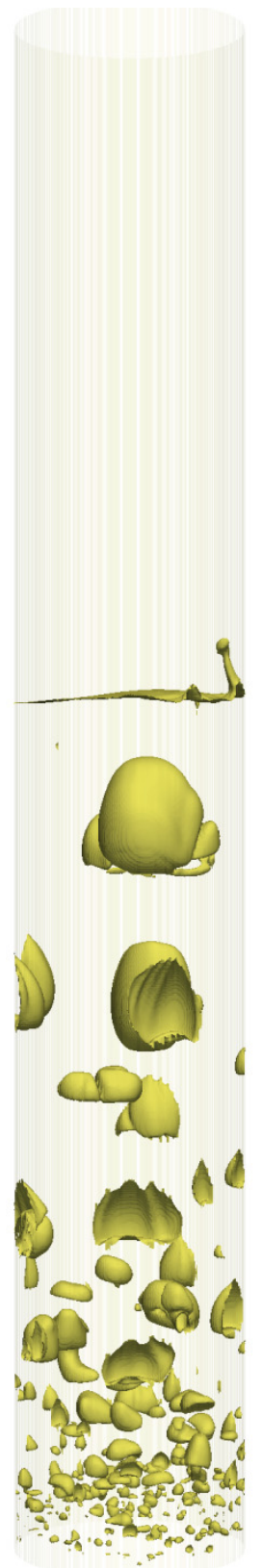

(a)

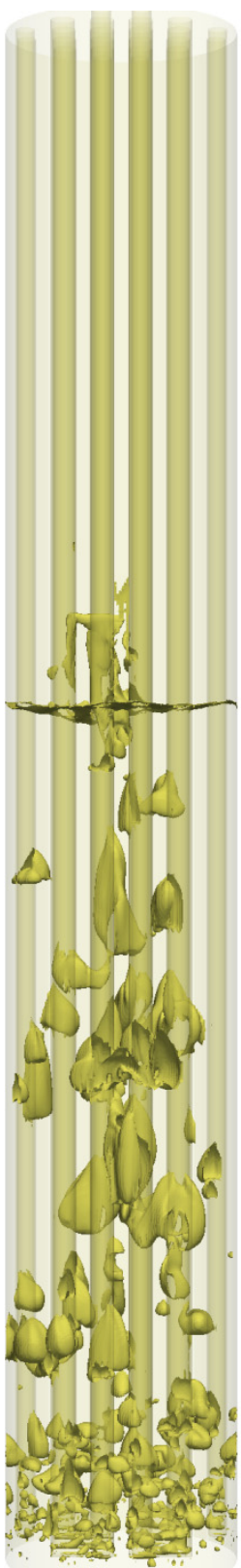

(b)

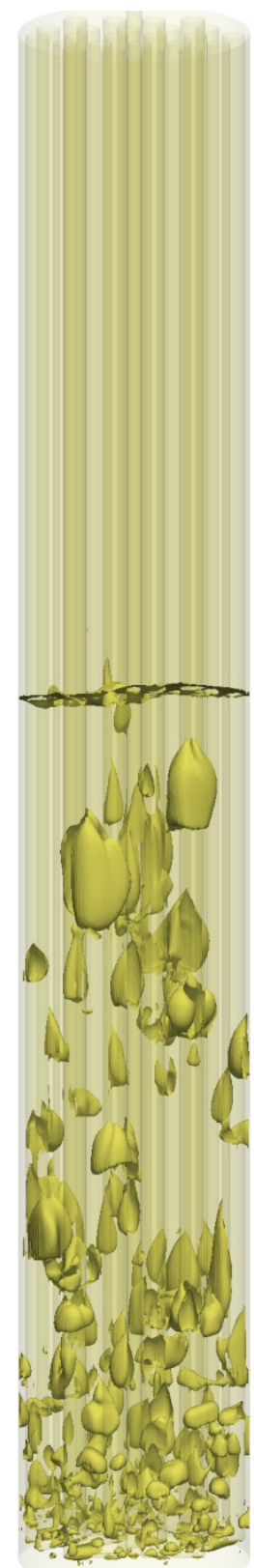

(c)

3 Fig. 6. Randomly selected instantaneous 3D bubble contours $\left(\phi_{\mathrm{g}}=0.80\right)$ for (a) bed without tubes, (b)

4 with tubes in a square arrangement, and (c) with tubes in a triangular arrangement, for inlet gas velocity 5 of $\mathrm{U}_{0} / \mathrm{U}_{\mathrm{mf}}=4.5$. 


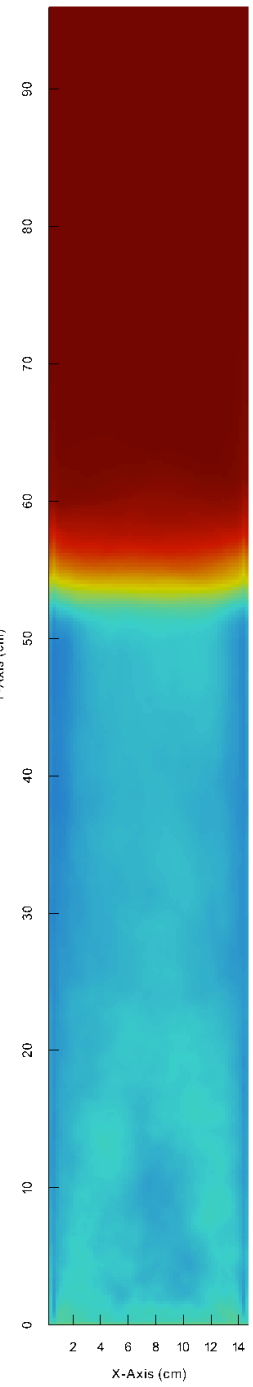

(a)

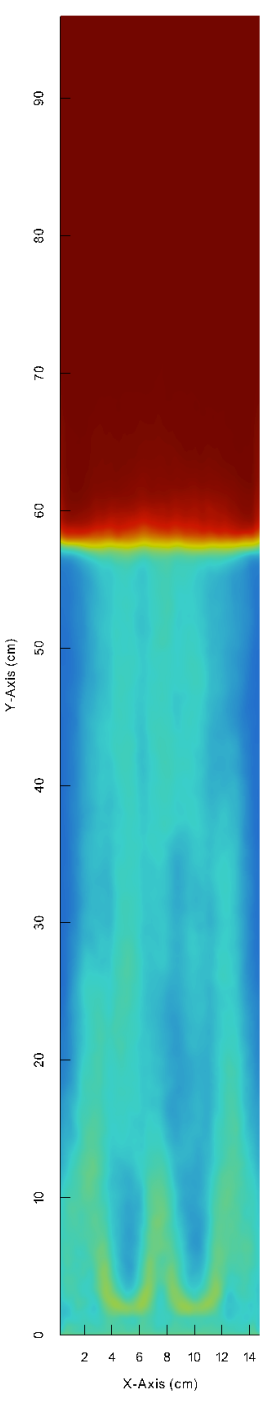

(b)

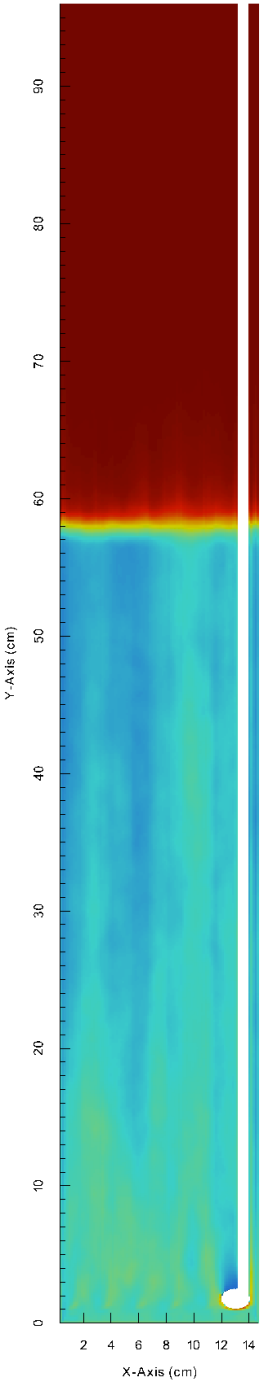

Time-averaged gas fraction (-)

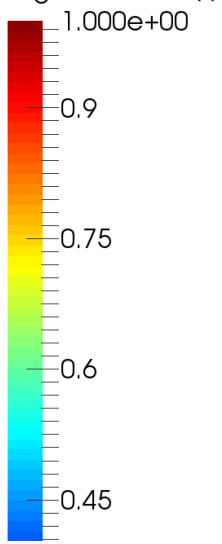

6 Fig. 7. Time-averaged porosity plot in a measurement plane, in a bed (a) without tubes, (b) with tubes in

7 square arrangement, and (c) with tubes in triangular arrangement, for inlet gas velocity of $\mathrm{U}_{0} / \mathrm{U}_{\mathrm{mf}}=4.5$. 

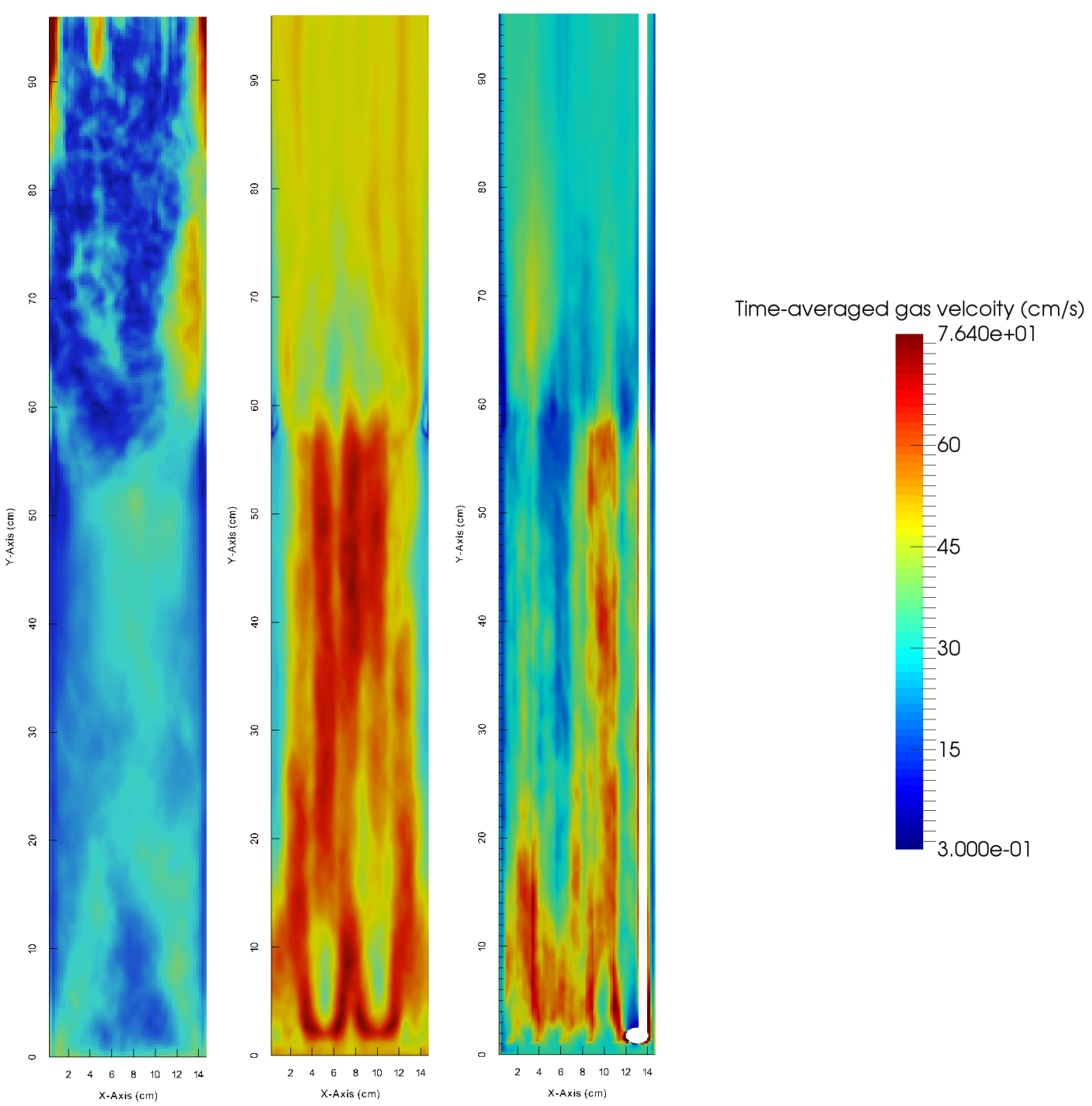

(b)

(c)

3 Fig. 8. Time-averaged axial gas velocity in a vertical measurement plane for a bed (a) without tubes, (b)

4 with tubes in a square arrangement, and (c) with tubes in a triangular arrangement for an inlet gas velocity 5 of $\mathrm{U}_{0} / \mathrm{U}_{\mathrm{mf}}=4.5$. 


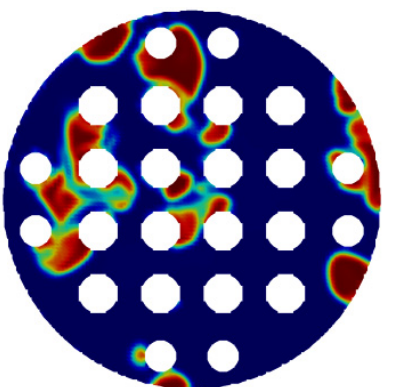

(a)

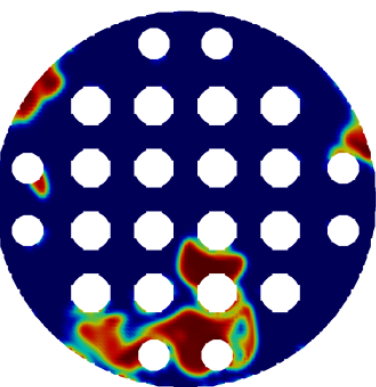

(b)
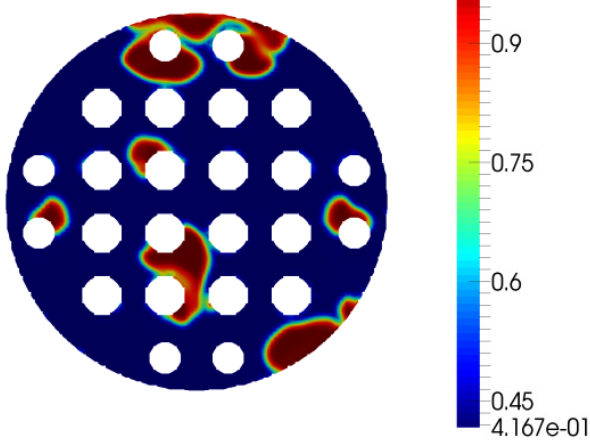

2

Fig. 9. Randomly selected instantaneous snapshots of gas volume fraction in a horizontal cross section for a bed with square tube arrangement: (a), (b) and (c) represent gas volume fractions at different times at a height of $0.2 \mathrm{~m}$ from the bottom for $\mathrm{U}_{0} / \mathrm{U}_{\mathrm{mf}}=4.5$.

(1)

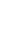

10

1

12

3

4

15

6



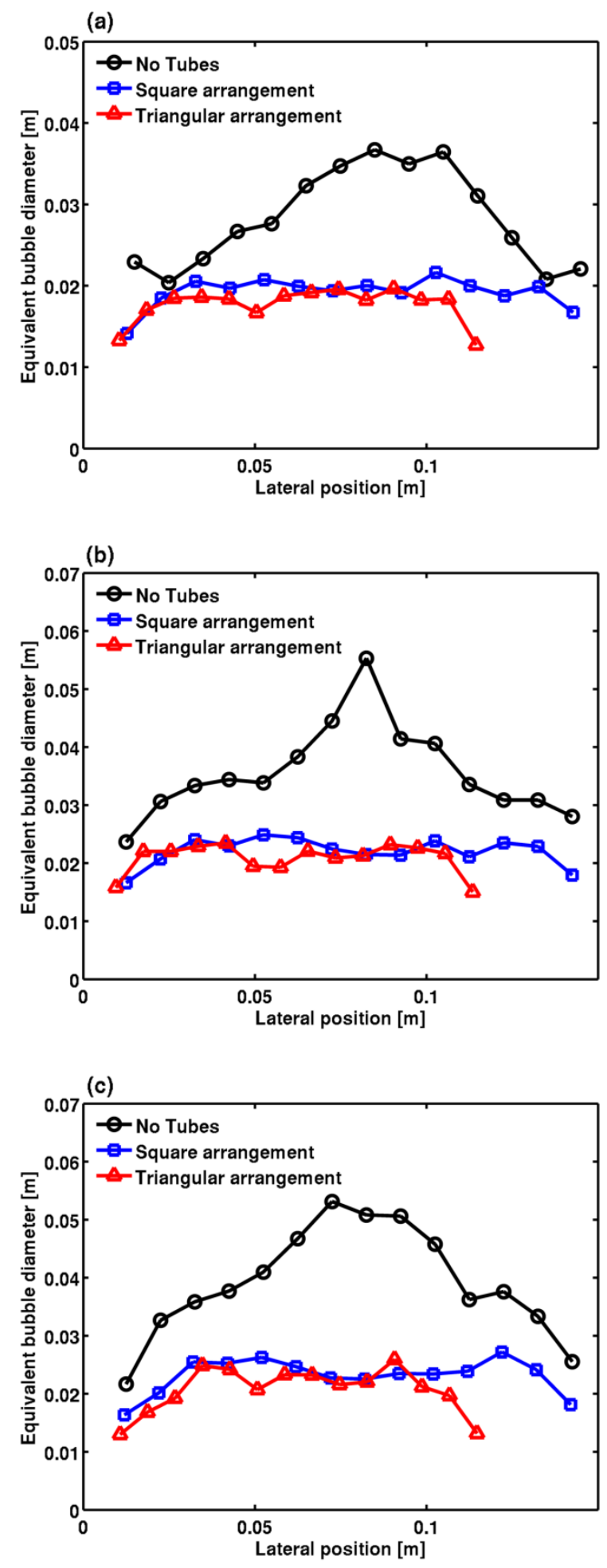

4 Fig. 10. Modeled equivalent bubble diameter as a function of lateral position averaged through the bed

5 height, comparing bed with and without tubes at operating inlet gas velocity of (a) $\mathrm{U}_{0} / \mathrm{U}_{\mathrm{mf}}=2.3$, (b)

$6 \quad \mathrm{U}_{0} / \mathrm{U}_{\mathrm{mf}}=4.5$, and (c) $\mathrm{U}_{0} / \mathrm{U}_{\mathrm{mf}}=6.8$. 

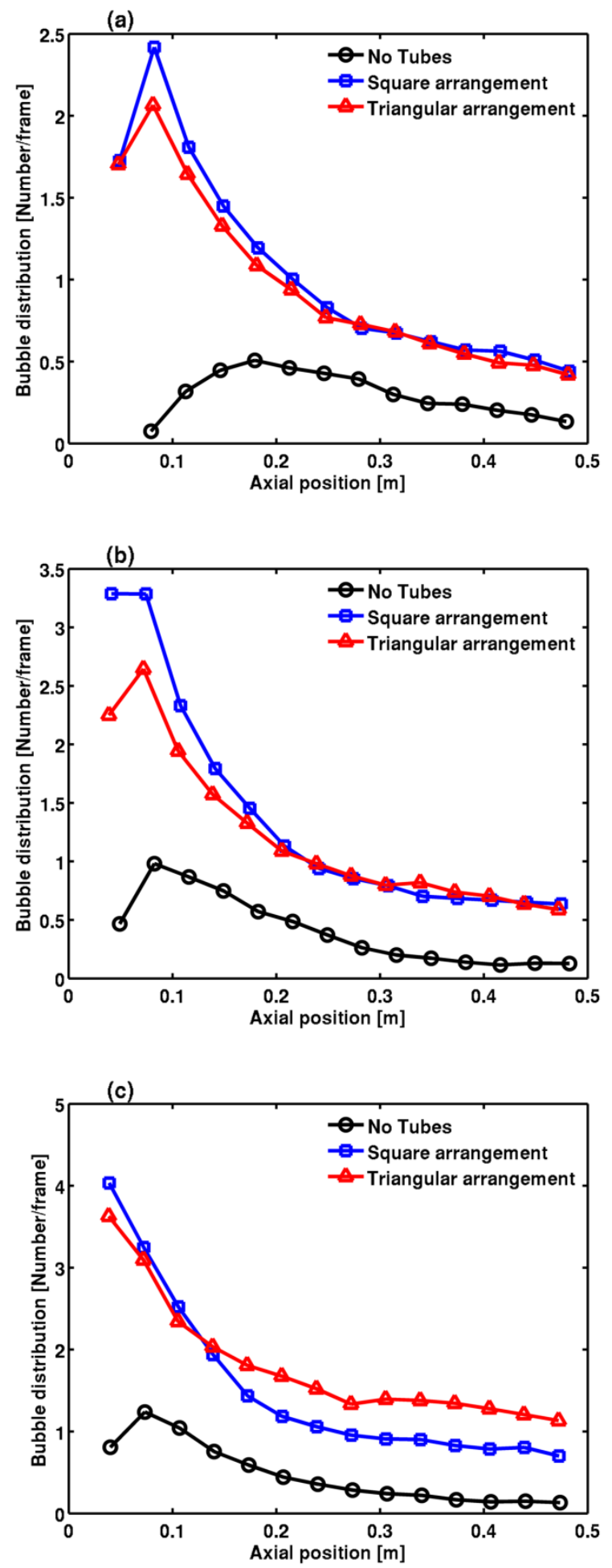

5 Fig. 11. Bubble distribution as a function of height from the, comparing bed with and without tubes at

6 operating inlet gas velocity of (a) $\mathrm{U}_{0} / \mathrm{U}_{\mathrm{mf}}=2.3$, (b) $\mathrm{U}_{0} / \mathrm{U}_{\mathrm{mf}}=4.5$, and (c) $\mathrm{U}_{0} / \mathrm{U}_{\mathrm{mf}}=6.8$. 

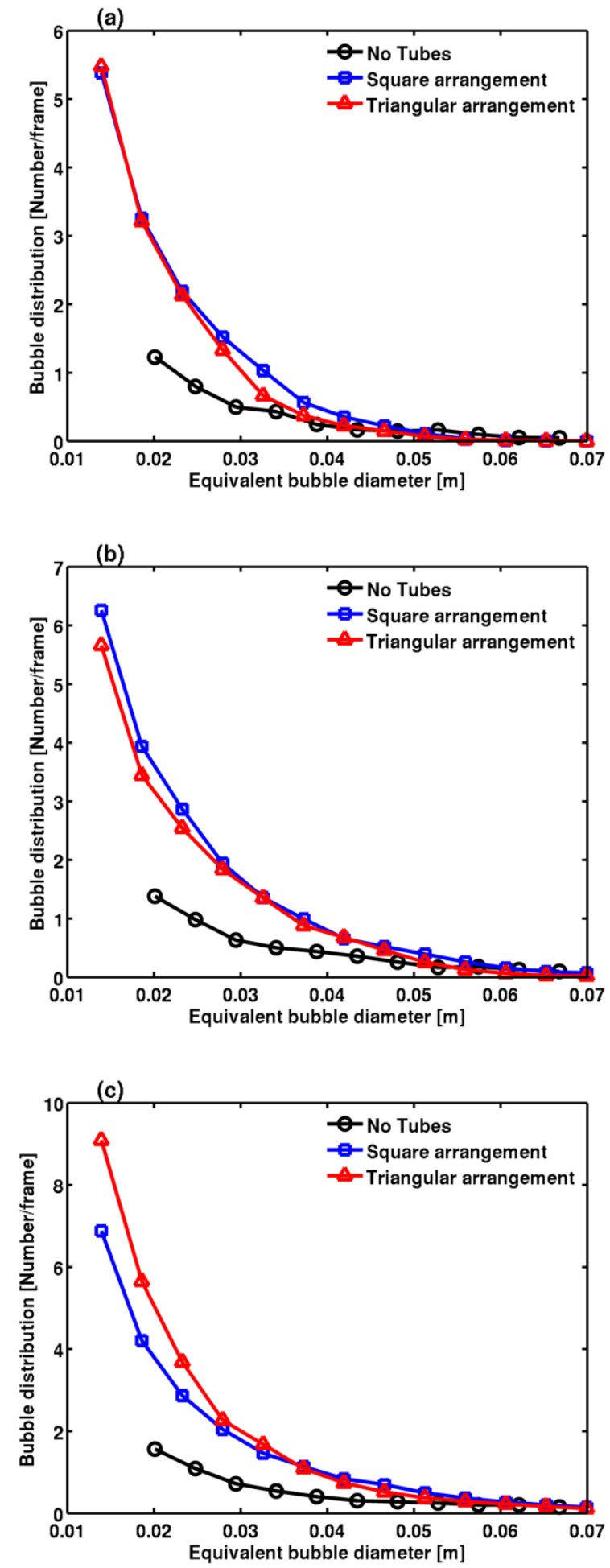

5 Fig. 12. Bubble distribution as a function of the equivalent bubble diameter, comparing bed with and

6 without tubes at operating inlet gas velocity of (a) $\mathrm{U}_{0} / \mathrm{U}_{\mathrm{mf}}=2.3$, (b) $\mathrm{U}_{0} / \mathrm{U}_{\mathrm{mf}}=4.5$, and (c) $\mathrm{U}_{0} / \mathrm{U}_{\mathrm{mf}}=6.8$. 

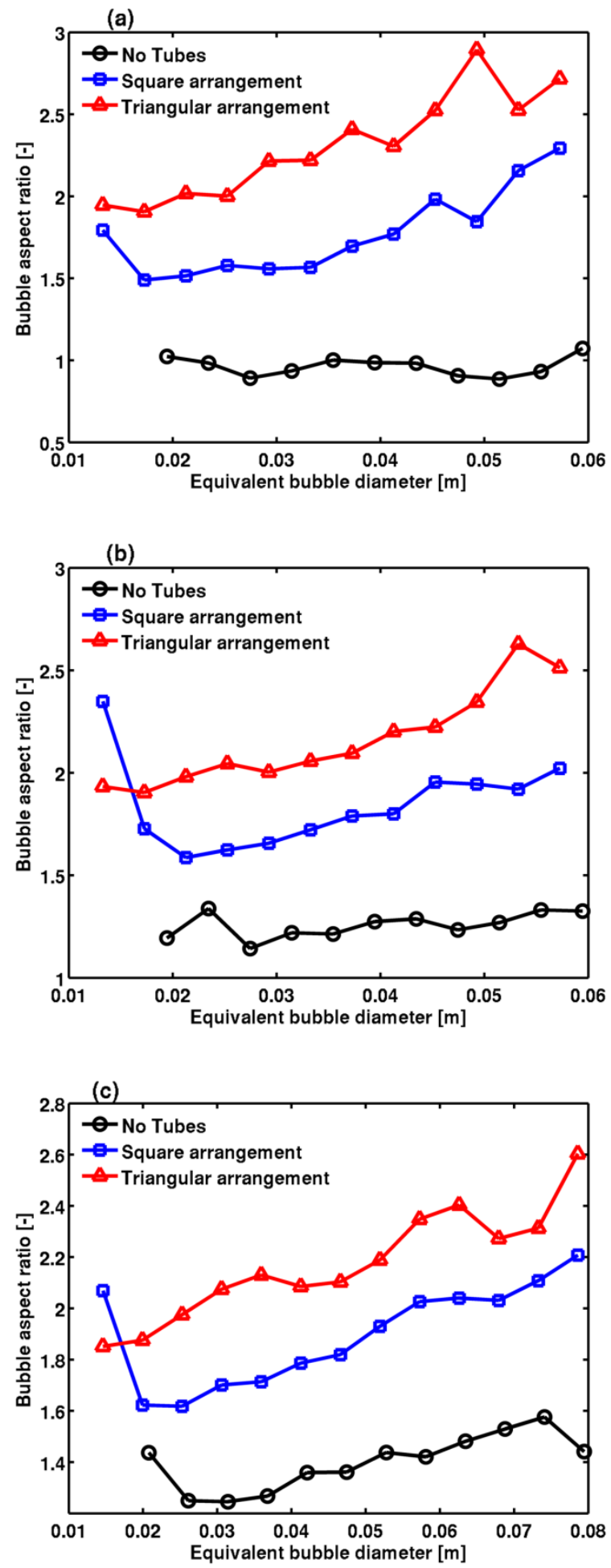

5 Fig. 13. Bubble aspect ratio as a function of the equivalent bubble diameter, comparing bed with and

6 without tubes at operating inlet gas velocity of (a) $\mathrm{U}_{0} / \mathrm{U}_{\mathrm{mf}}=2.3$, (b) $\mathrm{U}_{0} / \mathrm{U}_{\mathrm{mf}}=4.5$, and (c) $\mathrm{U}_{0} / \mathrm{U}_{\mathrm{mf}}=6.8$. 

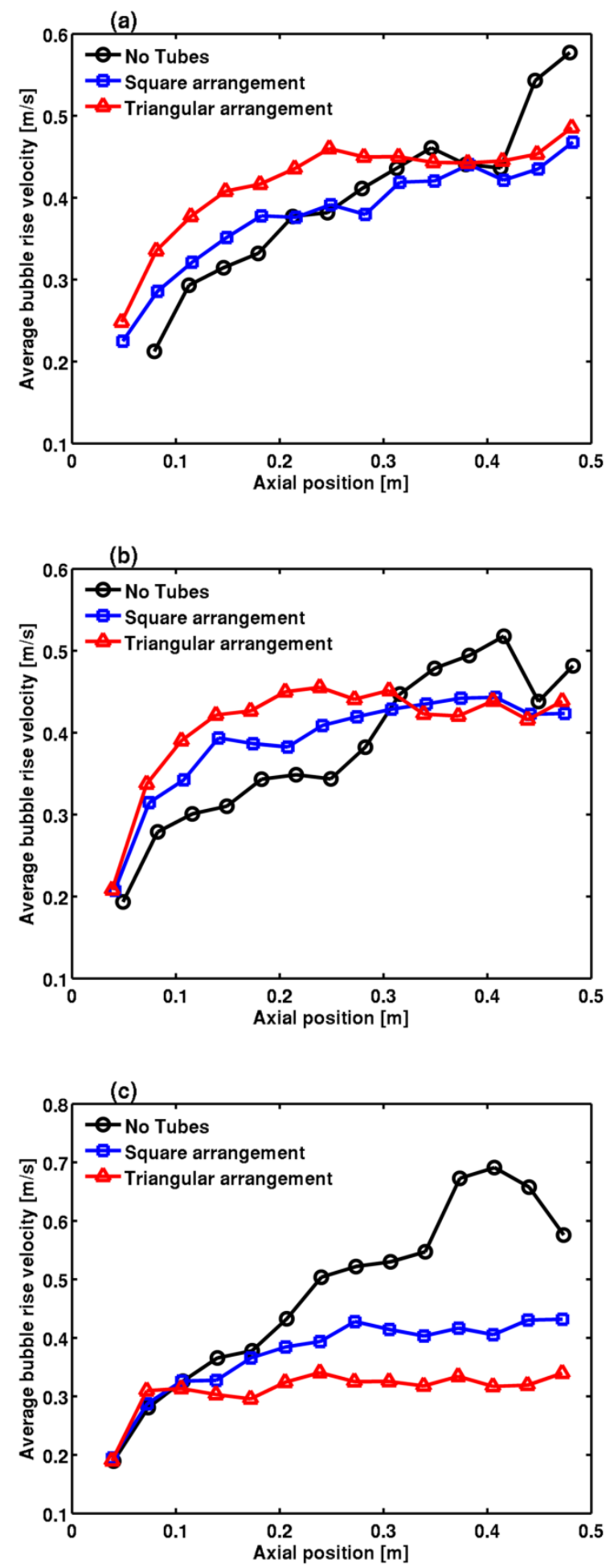

5 Fig. 14. Bubble rise velocity as a function of height from the bottom, comparing bed with and without

6 tubes at operating inlet gas velocity of (a) $\mathrm{U}_{0} / \mathrm{U}_{\mathrm{mf}}=2.3$, (b) $\mathrm{U}_{0} / \mathrm{U}_{\mathrm{mf}}=4.5$, and (c) $\mathrm{U}_{0} / \mathrm{U}_{\mathrm{mf}}=6.8$. 
(a)

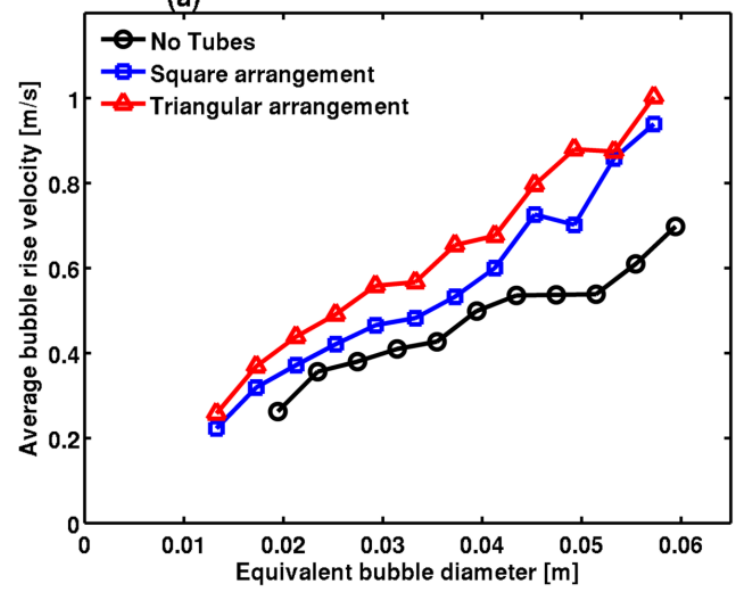

(b)

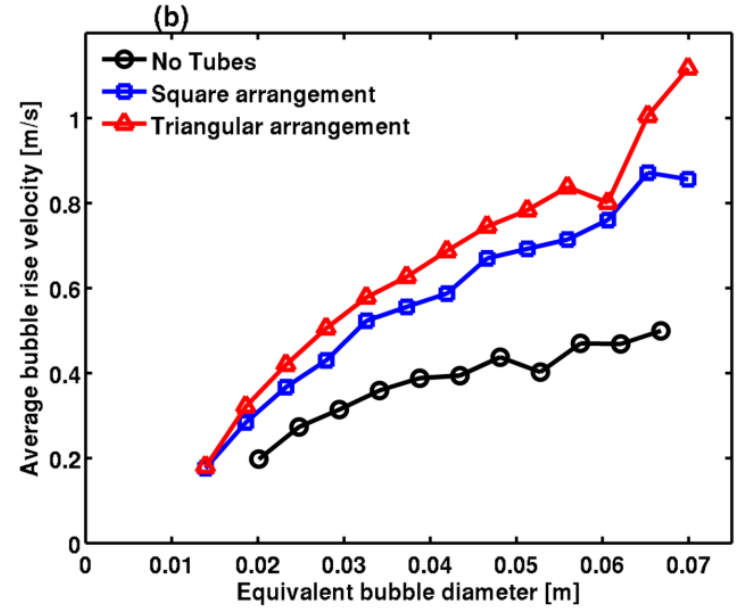

(c)

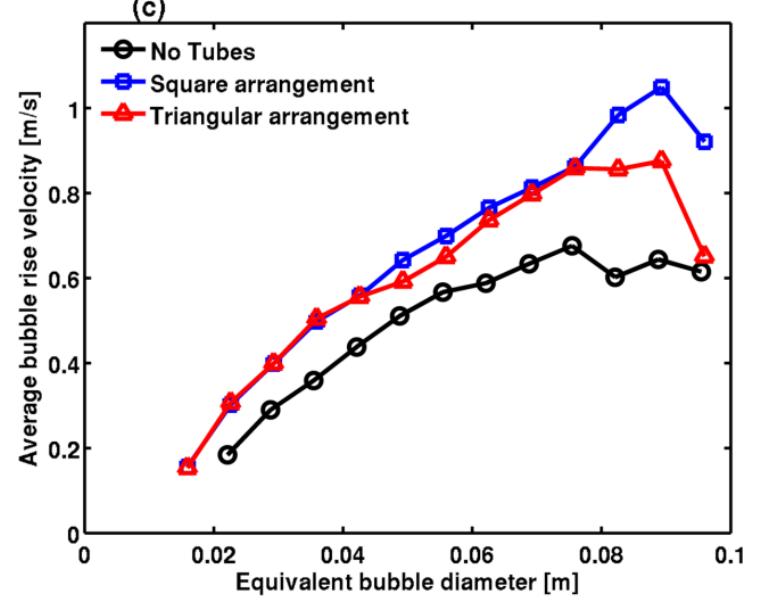

5 Fig. 15. Bubble rise velocity as a function of equivalent bubble diameter, comparing bed with and without

6 tubes at operating inlet gas velocity of (a) $\mathrm{U}_{0} / \mathrm{U}_{\mathrm{mf}}=2.3$, (b) $\mathrm{U}_{0} / \mathrm{U}_{\mathrm{mf}}=4.5$, and (c) $\mathrm{U}_{0} / \mathrm{U}_{\mathrm{mf}}=6.8$. 
(a)

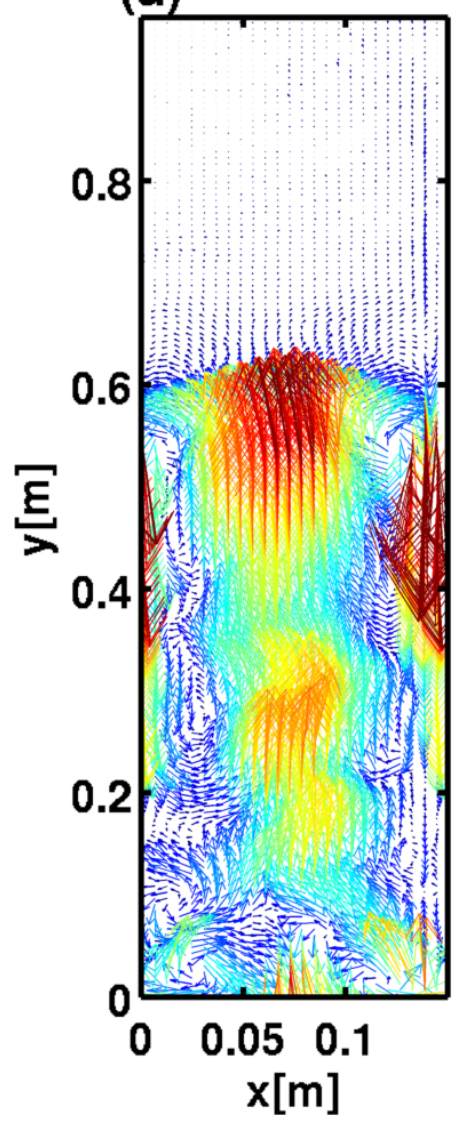

(b)

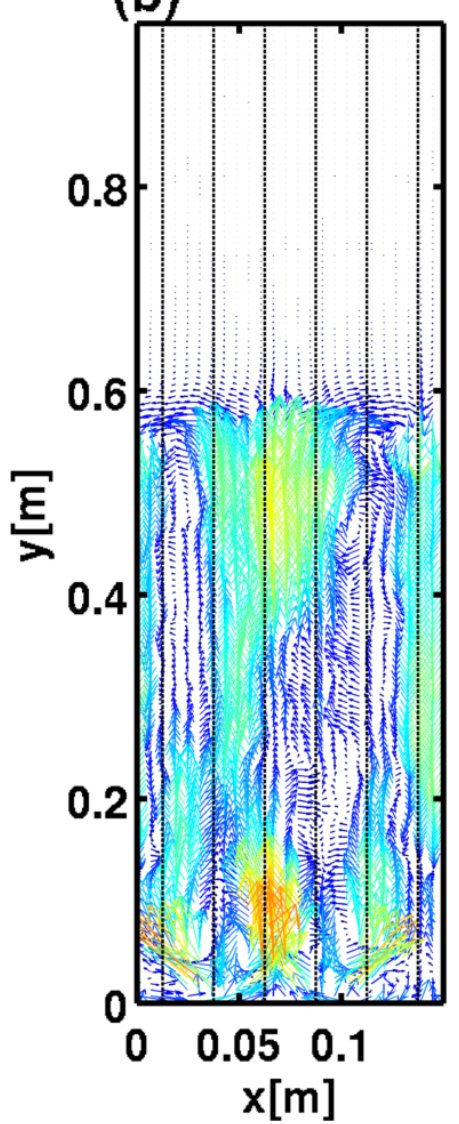

(c)

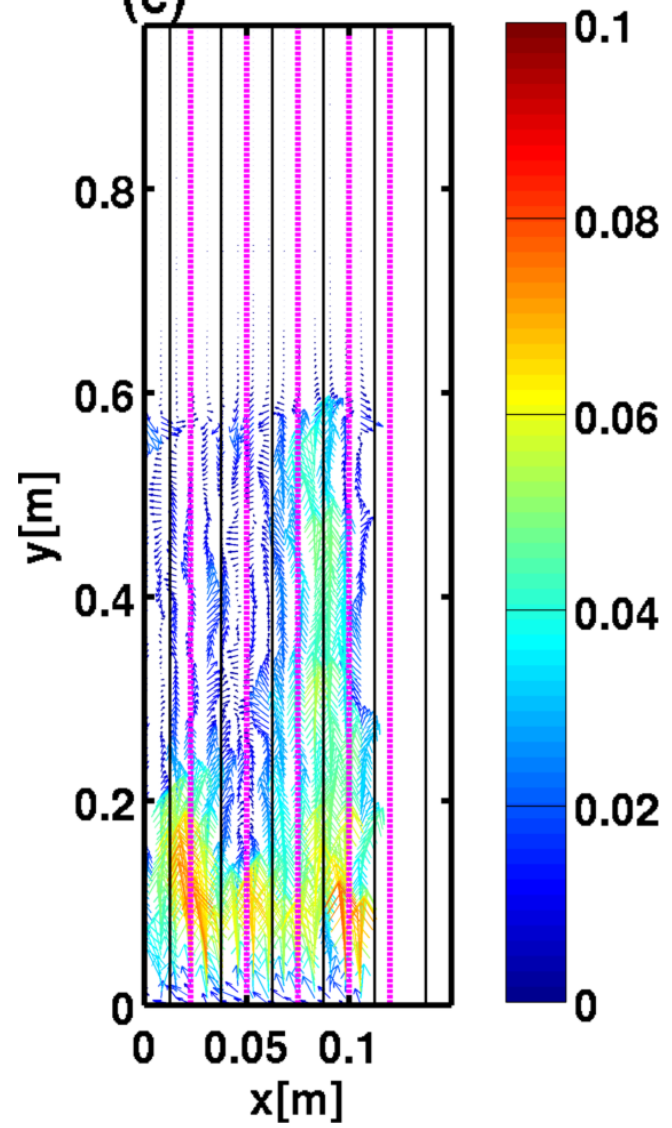

4 Fig. 16. Time-averaged solids circulation pattern at $\mathrm{U}_{0} / \mathrm{U}_{\mathrm{mf}}=4.5$ for a bed (a) without tubes, (b) tubes

5 with square arrangement, and (c) tubes with triangular arrangement. Vertical lines in (b) and (c) represent

6 locations of vertical tubes surrounding the measurement plane. In (c) vertical lines with different colors

7 represents tubes in front and back of the measurement plane, in (b) tubes in front and back plane are in

8 inline so these lines overlap. The color bar represents the magnitude of the solids velocity in $\mathrm{m} / \mathrm{s}$. 

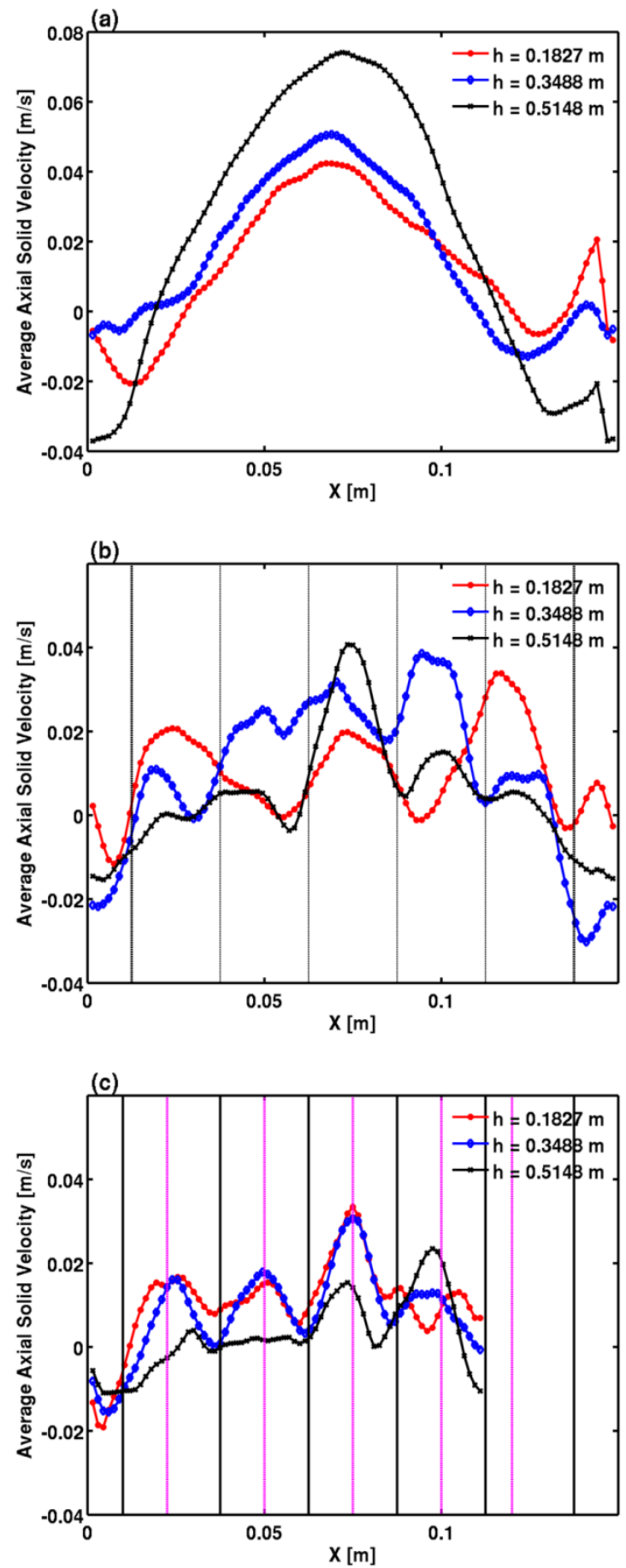

4 Fig. 17. Time-averaged axial solids velocity at $\mathrm{U}_{0} / \mathrm{U}_{\mathrm{mf}}=2.3$ for bed (a) without tubes, (b) tubes with

5 square arrangement, and (c) tubes with triangular arrangement, vertical line in (b) and (c) represent

6 location of vertical tubes surrounding the measurement plane. In (c) vertical lines with different color 
1 represents tubes in front and back of the measurement plane, in (b) tubes in front and back plane are in 2 inline so these line overlap.
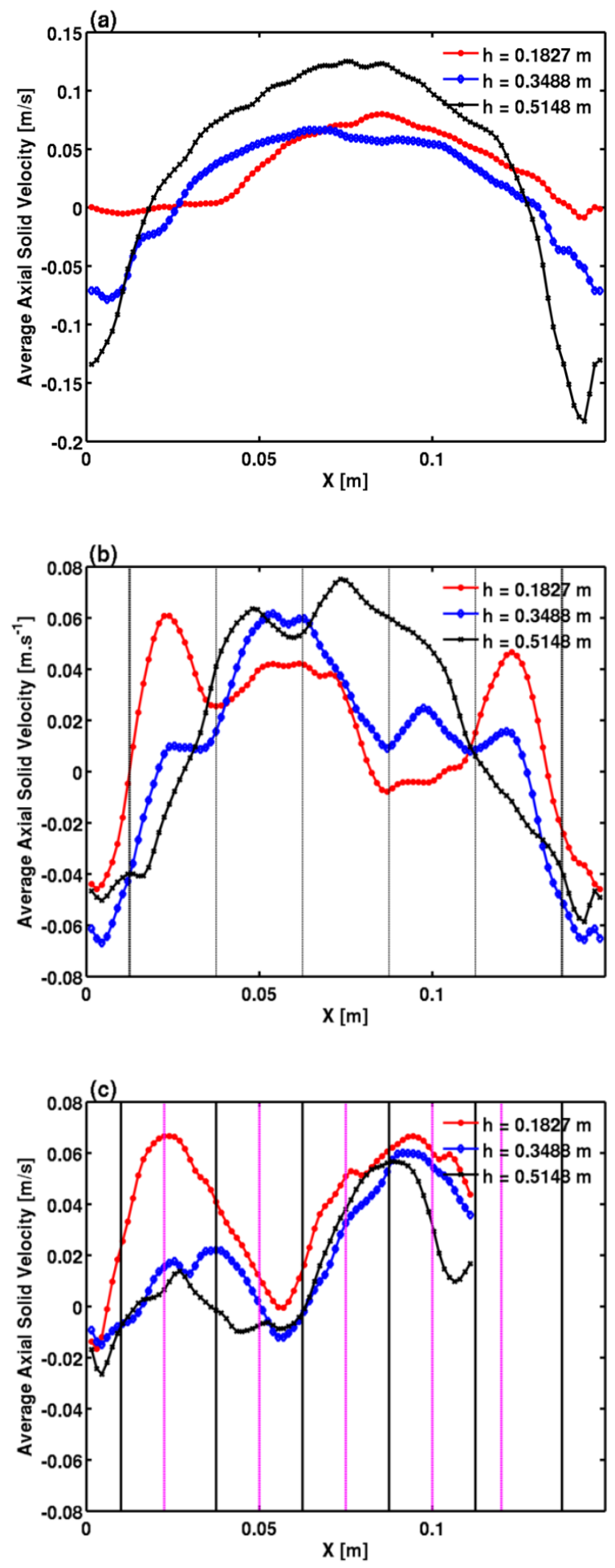
1 Fig. 18. Time-averaged axial solids velocity at $\mathrm{U}_{0} / \mathrm{U}_{\mathrm{mf}}=4.5$ for bed (a) without tubes, (b) tubes with 2 square arrangement, and (c) tubes with triangular arrangement, vertical line in (b) and (c) represent 3 location of vertical tubes surrounding the measurement plane. In (c) vertical lines with different color 4 represents tubes in front and back of the measurement plane, in (b) tubes in front and back plane are in 5 inline so these line overlap. 